\title{
Artificial Partisan Advantage in Redistricting ${ }^{\circ}$
}

\author{
Jon X. Eguia ${ }^{\S}$ \\ Michigan State University
}

September 12, 2020

\begin{abstract}
I propose a measure of artificial partisan advantage in redistricting. Redistricting is the process of drawing electoral district maps. Electoral outcomes depend on the maps drawn. The measure I propose compares the share of seats won by a party to the share of the population that lives in jurisdictions (counties and towns) won by this party. If a party has a larger share of seats than the share of the population in jurisdictions in which the party won most votes, then the drawing of the electoral maps conferred an artificial advantage to this party. This measure takes into account the geographic sorting of partisan voters and is simple to compute. Using U.S. election data from 2012 to 2018, I find an artificial partisan advantage of seventeen House seats to the Republican party. I argue that the artificial partisan advantage in the congressional maps of North Carolina, Utah, Michigan and Ohio is excessive.
\end{abstract}

\footnotetext{
'I thank A. Tybl, A. Earle and especially Christian Cox for diligent research assistance, and John Curiel for extensive discussions and valuable ideas. I am also grateful to C. Ahlin, S. Ansolabehere, J. Chen, M. Duchin, J. Katz, G. King, A. Miller, C. Smidt, N. Stephanopoulos, and participants at the 2019 PECA conference in Chicago, the Big 10 Alliance's SPARK conference in College Park, an Institute for Public Policy Social Research (IPPSR) public forum on redistricting in Lansing (Michigan), and at seminars at Michigan State U., New York U. and Harvard U. for their comments. I completed this draft while employed as a Visiting Associate Professor of Government at Harvard University. I gratefully acknowledge IPPSR for funding through a Michigan Applied Public Policy Research grant. I note that I volunteered for the organization Voters Not Politicians, which led the 2018 successful campaign for constitutional reform of redistricting in Michigan.
}

§Email: eguia@msu.edu 
"Partisan gerrymandering" is the practice of drawing electoral districts to favor a political party. The U.S. Supreme Court has found that partisan gerrymander is "unjust" and "incompatible with democratic principles." ${ }^{1}$ However, in 2019 the Court also found that "none of the proposed tests for evaluating partisan gerrymandering claims meets the need for a limited and precise standard that is judicially discernible and manageable."2

Traditional measures of partisan advantage in redistricting quantify the party asymmetry in how votes translate into seats. For instance, a map exhibits "partisan bias" (Butler 1952; Katz, King and Rosenblatt 2020) if one party obtains more seats than another for the same given vote share. $^{3}$ The Court questions whether much (or all?) of this partisan advantage can be explained by the geographic sorting of voters. "Consider, for example, a legislature that draws district lines with no objectives in mind except compactness and respect for the lines of political subdivisions. Under that system, political groups that tend to cluster (as is the case with Democratic voters in cities) would be systematically affected by what might be called a 'natural' packing effect."

To resolve this question, I propose a notion of partisan advantage that measures only the artificial partisan advantage caused specifically by the redistricting map, net of any natural

${ }^{1}$ Vieth vs Jubelirer 541 U.S. 267 (2004); Rucho v. Common Cause, No. 18-422, 588 U.S. (2019).

${ }^{2}$ Quoted from the Opinion of the Court in Rucho, as above.

${ }^{3}$ Other popular notions, discussed in the appendix and in Katz, King and Rosenblatt (2020), measure the difference between a party's vote share in the median district and its aggregate vote share, or compare the number of wasted votes for each party.

${ }^{4}$ Quoted from the Plurality Opinion in Vieth, as above. 
advantage due to population sorting. The measure of artificial partisan advantage is the number of seats that a party obtains in excess of a benchmark obtained by dividing the state into political jurisdictions such as counties, cities or townships, and assigning seats to each of these jurisdictions in proportion to its population. The jurisdictions used for this benchmark -either counties, or county subdivisions such as townships- are the one with jurisdictions closest in population size to the population represented by each seat in the assembly.

For US congressional elections, and with the exception of the very few most populous counties, the jurisdictions closest in size to congressional districts are the counties. Hence, the benchmark is the number of seats that the party would obtain if seats were assigned in proportion to the population residing in counties in which the party won the popular vote.

The benchmark based on jurisdictional units such as counties and townships has historic roots at the founding of American democracy: "Representation in the colonies was uniformly based on geographic units, whether towns, counties or parishes," with more populous jurisdictions often obtaining more delegates (Squire 2013). The founding fathers articulated that an ideal district must "preserve natural political communities, as institutionalized through the functional design of towns and counties" (Curiel and Steelman 2018). Indeed, at the time of the U.S. Constitutional Convention in 1787, the units of representation for the lower houses in twelve of thirteen states in the Union were the county or the town, and in several of these states, each of these jurisdictional units received seats in proportion to its population (Kromkowski 2002, Table 5.6; Pole 1966). 
For instance, under Pennsylvania's 1776 Constitution, each county (and the city of Philadelphia) was an electoral district, assigned seats in the General Assembly "in proportion to the number of taxable inhabitants" (Const. of Pennsylvania, Section 17). If we substitute "person" for "taxpayer", the benchmark to define the artificial partisan advantage is constructed as designed by the founders of the State of Pennsylvania.

In a representative democracy in which each representative represents a defined geographic area, States can satisfy the "one-person, one-vote" principle of equal representation ${ }^{5}$ by either of two methods: apportioning, or redistricting. Apportioning preserves a fixed map of jurisdictions and assign seats or voting weight to each jurisdiction in proportion to its population. ${ }^{6}$ Redistricting apportions one seat and one vote per district and redraws district boundaries as needed to equate population across districts. Given a fixed map of jurisdictions, there is only one apportionment consistent with equal representation, and hence only one possible split of seats across parties. In contrast, given a fixed apportionment of one seat per district, there are millions of possible redistricting maps, and hence many possible seat splits across parties.

Congress first mandated single-member districts (ruling out the apportionment method) for federal elections in $1842 .^{7}$ The normative underpinning of the artificial partisan advantage

${ }^{5}$ Reynolds v. Sims, 377 U.S. 533 (1964).

${ }^{6}$ The US Electoral College, and the qualified majority rule in the European Council, follow this method.

7 Multi-member districts remain legal for state legislatures, so redistricting is optional. For instance, the district for elections to the senate of Vermont are based on Vermont's counties, and more populous counties are apportioned more seats to their district (up to six). 
measure is that the congressional choice to require single-member districts, which prompted the need to redistrict, should preserve the balance of political power that would materialize were states to return to the historical precedent of using apportionment with fixed jurisdictions instead. Any seats obtained with a given redistricting map in excess of those that would accrue to a party under the apportionment method, constitute a map-driven artificial advantage.

In the next section I discuss the judicial background on partisan gerrymandering. In Section 3 I precisely define the measure of artificial partisan advantage and how to compute it; in Section 4 I present some results for the 2012-2018 cycle of elections; and in Section 5 I discuss alternative measures of partisan fairness, with tables in the Appendix. I relegate to an online appendix the following ancillary material:

i) A state-by-state detailed discussion, for selected states of greatest interest.

ii) An extensive discussion of caveats and limitations of the proposed measure.

\section{JUDICIAL BACKGROUND ON PARTISAN GERRYMANDERING}

"Gerrymandering" refers to the practice of drawing district maps to favor one party or class. The Voting Rights Act of 1965 declared it illegal to gerrymander on racial grounds in such a way that dilutes the vote of a racial minority, and subsequent decisions by the Supreme Court of the United States (henceforth, "SCOTUS") have also limited the practice of drawing maps that artificially pack minority voters together. ${ }^{8}$

\footnotetext{
8 Shaw v. Reno, 509 U.S. 630 (1993), Miller v. Johnson, 515 U.S. 900 (1995), Bush v. Vera, 517 U.S. 952 (1996).
} 
Recently, attention has shifted to partisan gerrymanders: is it permissible to draw maps to reduce the representation of Democratic or Republican voters?

In Davis vs Bandemer 478 U.S. 109 (1986), SCOTUS held that claims that a redistricting map is a political gerrymandering are justiciable; that is, the courts can resolve these claims and can strike down maps that provide too much partisan advantage to one party. However, SCOTUS could not agree upon a test or measure of what constitutes an excessive partisan advantage to actually adjudicate such claims.

In Vieth vs Jubelirer (2004), a plurality Opinion by Justice Scalia argued "there are no existing manageable standards for measuring [...] a political gerrymander", and hence that partisan gerrymandering is a political question that is not subject to judicial review. ${ }^{9} \mathrm{~A}$ minority of four justices disagreed, proposing various such standards. In his decisive Opinion concurring in the judgment, Justice Kennedy rejected all the proposed standards and agreed that an "easily administrable standard" did not exist, but he also crucially held that the desired standard could be found in the future: "that no such standard has emerged in this case should not be taken to prove that none will emerge in the future." 10 Therefore, claims that a redistricting map is a partisan gerrymandering remained justiciable, pending the development of an appropriate standard.

${ }^{9}$ Vieth vs Jubelirer 541 U.S. 267 (2004), quoting from the syllabus.

10 Vieth vs Jubelirer 541 U.S. 267, 310-311 (2004). 
In LULAC V Perry (2006), the majority Opinion by Justice Kennedy reaffirmed that the Courts can, in principle, determine whether a redistricting map is an illegal partisan gerrymander, but in practice it once again failed to find the necessary but elusive "reliable standard for identifying unconstitutional political gerrymanders."11

Between 2016 and 2019, a sequence of federal district court rulings struck down the state legislative maps of Wisconsin, and the congressional maps of North Carolina, Maryland, Michigan and Ohio, all of them ruled unconstitutional partisan gerrymanders. ${ }^{12}$

In June 2019, SCOTUS overturned the lower court rulings in the North Carolina and Maryland cases, ruling that claims of partisan gerrymander are "not justiciable" under federal law; that is, they cannot be addressed or adjudicated in federal courts. In the Opinion of the Court, Chief Justice Roberts explains that we "lack judicially discoverable and manageable standards for resolving [partisan gerrymandering cases]."

Roberts' Opinion of the Court in Rucho v. Common Cause concedes that: "Excessive partisanship in districting leads to results that reasonably seem unjust" and states as a fact that "such gerrymandering is incompatible with democratic principles." While it concludes that federal courts cannot address the problem, it argues that this conclusion "does not condone excessive

${ }^{11}$ League of United Latin American Citizens vs Perry 548 U.S. 399, 423 (2006).

12 The cases are Whitford v. Gill, 218 F. Supp. 3d 837 (W.D. Wis. 2016) in Wisconsin; Common Cause v. Rucho, 279 F. Supp. 3d 587 (M.D.N.C. 2018) in North Carolina; Benisek v. Lamone, 348 F. Supp. 3d 493 (D. Md. 2018) in Maryland; League of Women Voters v. Benson, No. 2: 17-cv14148 (E.D. Mich. Apr. 25, 2019) in Michigan; and Phillip Randolph Institute v. Householder, No. 1: 18-cv-357 (S.D. Ohio May 3, 2019) in Ohio. 
partisan gerrymandering." SCOTUS finds a solution instead in state courts: "Provisions in state statutes and state constitutions can provide standards and guidance for state courts to apply."

Roberts' Opinion of the Court cites Florida, where in 2015, the state's Supreme Court "struck down that State's congressional plan as a violation of the 'Fair Districts Amendment' to the Florida Constitution." ${ }^{13}$ The Opinion also highlights several other states -including Michigan, Missouri, lowa and Delaware- where state legislation prohibits partisan favoritism explicitly. For instance, see the lowa Code 42.4(5) (2016): “No district shall be drawn for the purpose of favoring a political party, incumbent legislator, or member of Congress, or any other group." Fourteen states (California, Colorado, Delaware, Florida, Hawaii, Idaho, lowa, Michigan, Missouri, Montana, New York, Ohio, Oregon and Washington) include explicit provisions against partisan advantage in redistricting in their state constitutions. ${ }^{14}$ Partisan gerrymanders in any of these states can be challenged in state courts as violations of these state provisions.

Legal challenges in state courts may also succeed in states without such explicit prohibitions. For instance, the Pennsylvania Supreme Court ruled in 2018 that the 2011 Pennsylvania congressional maps "clearly, plainly and palpably" violate the Pennsylvania constitution, in particular the "free and equal elections" clause in Art. I Sec. 5, by favoring the Republican party,

\footnotetext{
13 Pages 30 and 31 of Rucho v. Common Cause, No. 18-422, 588 U.S. __ (2019). The Florida case was League of Women Voters of Florida v. Detzner 172 So. 3d 363 (2015).

${ }^{14}$ I provide a summary of these provisions in Table A.1 in the Appendix.
} 
and ordered a new set of maps drawn for the 2018 congressional election. ${ }^{15}$ Similarly, in 2019 , state courts in North Carolina struck down the North Carolina congressional and state legislative maps, finding them in violation of Art. I of the North Carolina Constitution, which mandates that "elections shall be free."16

With action in federal courts precluded for the foreseeable future, further litigation over partisan gerrymandering appears likely in states' courts during the next redistricting cycle (20212030).

\section{DEFINITION OF THE ARTIFICIAL PARTISAN ADVANTAGE MEASURE}

Consider a state $S$, and an assembly $A$ in which state $S$ has a delegation of $k$ seats. Consider a given redistricting map $m$ that divides state $S$ into $k$ districts with approximately equal population. Consider a given voting profile $v$, which indicates how each citizen voted. For each party $p$ that competes in state $S$, let $s_{p}(v, m)$ denote the number of seats that party $p$ wins, given the voting profile $v$ and the redistricting map $m$.

Given the voting profile $v$ and a benchmark number of seats $s_{p}(v)$ for party $p, I$ define the artificial partisan advantage that map $m$ gives to party $p$ relative to this benchmark, as

$$
s_{p}(v, m)-s_{p}(v)
$$

\footnotetext{
${ }^{15}$ League of Women Voters of Pennsylvania v. Commonwealth of Pennsylvania 178 A.3d 737 (2018).

${ }^{16}$ Harper v. Lewis 19 CVS 012667 Wake County Superior Court; and Common Cause v. Lewis 358 F. Supp. 3d 505 (D.N.C. 2019).
} 
To construct the benchmark, I use the existing division of the state into jurisdictional units such as counties, cities and townships, and in particular, using in each case the jurisdictional unit closest in population size to the districts that need to be drawn.

Congressional districts represent approximately 710,000 residents each, and the jurisdictional unit closest in size -with few exceptions discussed below- is the county. Hence, for most states, I use the state's county map. For each county, I credit the total county population to the party that wins the most votes in the county, and aggregating across counties, the benchmark $s_{p}(v)$ is proportional to the total population in counties in which party $p$ won the popular vote. ${ }^{17}$

The exception are counties with population size greater than two congressional districts, that is, over $1,415,000$ inhabitants. Out of the 2,844 counties in the 42 states in which I measure the artificial partisan advantage, only 23 are of population size greater than two congressional districts. In these large counties, if each party is a local majority in a different area of the county, each party could win one or more districts within the county. Crediting the whole county to the county-wide majority party would hide this minority, biasing the results. Wherever possible, I correct this problem by splitting these large counties into smaller jurisdictional units, by iteratively taking out their largest cities or townships and treating them as independent units, until the population in the remainder of the county is less than $1,415,000$. Table A.3 in the Appendix lists the resulting collection of jurisdictional units after splitting the largest counties in this manner. ${ }^{18}$

\footnotetext{
17 Table A.2 in the Appendix illustrates this procedure for New Hampshire in 2018.

18 I split nineteen large counties into cities and townships: Alameda, Los Angeles, Orange, Riverside, Sacramento, San Bernardino, San Diego and Santa Clara in California; Bexar, Dallas,
} 
Formally, given this set of jurisdictional units $U$ in state $S$, for each jurisdictional unit $u$ in $U$ in state $S$, let $n_{u}$ denote the population in $u$, and let $n$ be the total population in the state. For each party $p$, each district $d$ and each jurisdictional unit $u$, let $v_{p}(u, d)$ be total number of votes that party $p$ obtains in the precincts of district $d$ that lie within unit $u$. Party $p$ wins in unit $u$ if its sum of votes across all precincts in unit $u$ is the greatest, that is, if $\sum_{d} v_{p}(u, d)>\sum_{d} v_{p \prime}(u, d)$ for any other party $p^{\prime}{ }^{19}$

Then I calculate the natural number of seats $s_{p}(v)$ by assigning $\frac{n_{u}}{n} k$ seats to party $p$ for each jurisdictional unit $u$ in $U$ in which party $p$ won the popular vote given the election results $v$, where $k$ is the total number of seats to assign.

This procedure can be summarized by the following definition of artificial partisan advantage:

Definition: Given a partition of a state into the jurisdictions closest in size to the districts to be drawn, the artificial partisan advantage conferred by a redistricting map to a given party is the difference between the seats the party obtains, and the seats that correspond to the party in proportion to the total population of the collection of jurisdictions in which the party won the popular vote.

Harris and Tarrant in Texas; Maricopa in Arizona, Cook in Illinois; Middlesex in Massachusetts; Wayne in Michigan; Clark in Nevada; Suffolk in New York, and King in Washington. The four counties that cannot be split into cities or townships are Kings, New York and Queens in New York (because they are themselves boroughs within the City of New York), and Philadelphia, because the city and the county coincide.

${ }^{19}$ Ties are unlikely, and rare. If a tie occurs, I assign half the population of the unit to each party. 
While choosing the jurisdictions closest in size to the districts to be drawn best aligns the level of aggregation in the benchmark to the one in the actual electoral maps, as a robustness check, we can also compute variants of the artificial partisan advantage using coarser or finer partitions of the state into larger or smaller jurisdictions. I pursue these robustness checks, computing the resulting measure for all states only using county subdivisions for counties with population greater than that of three, four or five congressional districts, and, for the states and elections for which the data is readily available, aggregating by townships or by precincts. ${ }^{20}$

\section{DATA AND RESULTS}

I compute the artificial partisan advantage in the 2012, 2014, 2016 and 2018 elections to the US House of Representatives. There are 43 states that draw district maps, because they have at least two delegates. I exclude Florida because it does not hold elections for uncontested races, so it does not provide the data about the winners' support necessary to compute the measure. For the 2018 election I exclude Maine as well, because in 2018 it changed its electoral rule to Alternative Vote. Therefore, I compute the artificial partisan advantage for 42 states for the 2012, 2014 and 2016 elections, and for 41 states for the 2018 election.

\footnotetext{
${ }^{20} \mathrm{As}$ I report in the online Appendix, the main results (the aggregate partisan advantage, and the states with the greatest advantage) are qualitatively robust across levels of granularity in the jurisdiction map used to construct the benchmark. Taking these robustness checks to the limit, the smallest level of aggregation is at the individual level (no aggregation at all), and corresponds to a proportional representation benchmark; whereas, the highest level of aggregation, at the state level, corresponds to a winner-takes-all seat allocation.
} 
Population data by county is from the 2010 US Census and is publicly available from the US Census Bureau. Election results data is publicly available from each state's Secretary of State. I use election results from the 2012, 2014, 2016 and 2018 elections to the US House of Representatives for the main analysis, and results from the 2012 and 2016 US Presidential election as a robustness check discussed at the end of the section. ${ }^{21}$

In the aggregate across all states, and on average across all four elections the net Republican aggregate artificial partisan advantage is seventeen seats. Disaggregating by election, but still aggregating across all states, the net artificial partisan advantage for the Republican party was twenty-five seats in 2012, five in 2014, seventeen in 2016 and twenty-two in $2018 .^{22}$

Figure 1 compares the actual number of Republican seats in the House of Congress as a function of the Democratic vote share, to the total number of Republican seats if in the states in the sample we substitute the number of Republican seats according to the jurisdiction-based benchmark for the actual Republican seats. For an election in which the Republican party wins by a large margin (such as in 2014), there is very little artificial partisan advantage. The advantage materializes only as the electoral returns of the Republican party deteriorate: as the Democratic vote

\footnotetext{
${ }^{21}$ I use the original, publicly available data from state clerk's offices for the 2018 election, and for all years for states with a top-two primary (California, Washington and Louisiana). For convenience, for the 2012, 2014 and 2016 elections in all other 39 states, I use the compilation available from Dave Leip's Election Atlas. Data to split the large counties come directly from the counties' clerk's offices.

${ }^{22}$ The sharp decrease in the Republican partisan advantage from 2012 to 2014 is discussed by Goedert (2015).
} 
share increases from $47 \%$ to just over $50 \%$, many counties flip, but very few districts do so, and the gap between the number of seats won by Republicans, and the number of seats according to the jurisdiction-based benchmark widens.

The elasticity of the jurisdiction-based Republican seat benchmark with respect to the Democratic vote share from the 2014 result (47\% Democratic) to the 2012 result (50.6\% Democratic) is -2.16. But the elasticity -or "responsiveness"- of actual Republican seats with respect to Democratic vote share is only -0.85 .

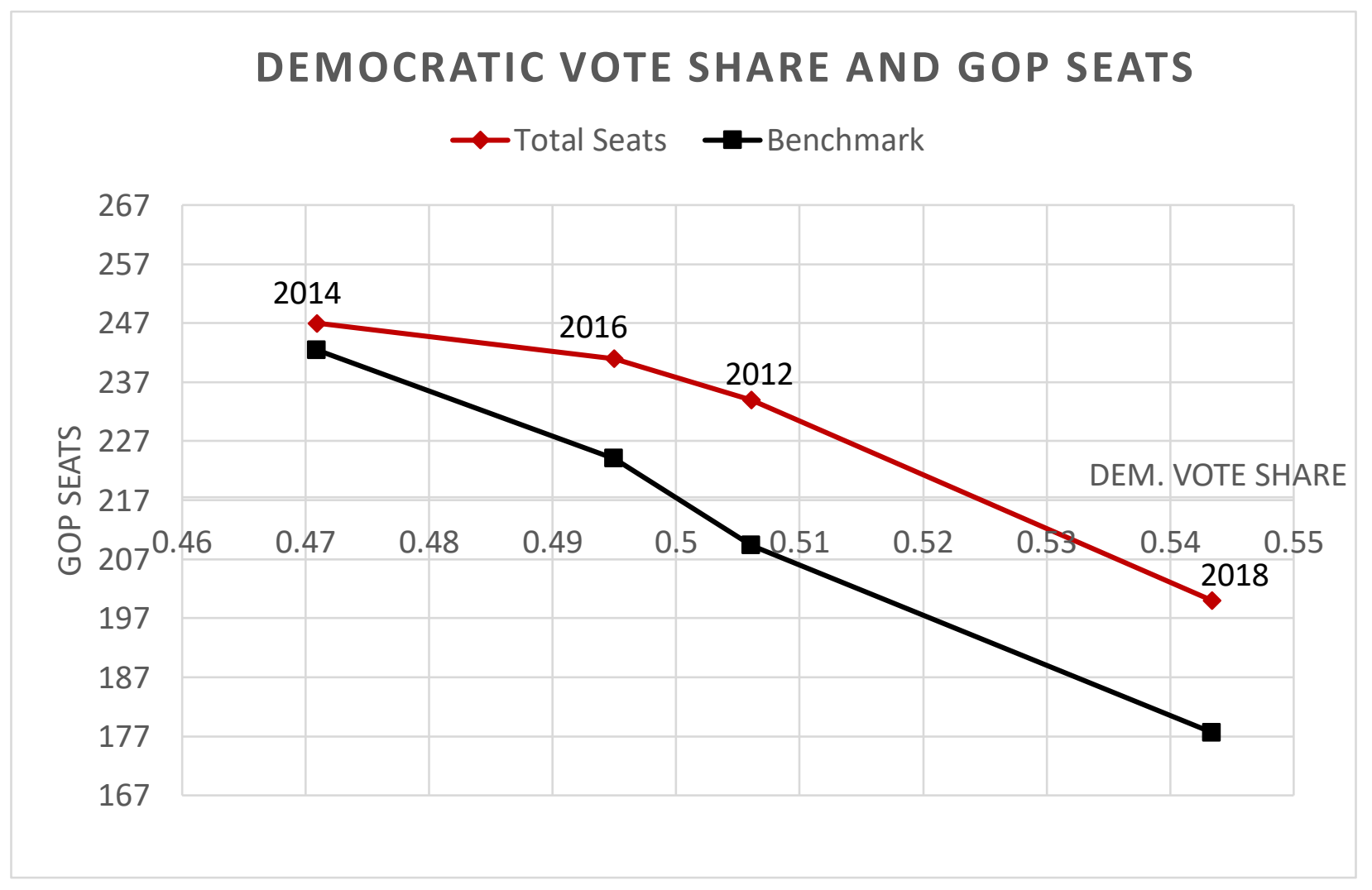

Figure 1 GOP benchmark and total seats as a function of the Dem. national vote share.

The consequence is that under the 2011 redistricting maps, elections in which the Republican party wins the national popular vote by a little (as in 2016) or loses it by a little (as in 2012), deliver a seat outcome similar to the one if the Republican party wins by a lot (as in 2014). 
Computing the benchmark number of seats according to jurisdictional units allows us to answer the following question: how much of the partisan bias in favor of the GOP is due to natural factors such as the geographic sorting of voters, and how much is artificial, due to drawing biased maps? To answer this question, we can compute the partisan bias (the deviation from symmetry) of the benchmark itself. If the popular vote in an election is tied, the population in jurisdictional units won by each party will not be tied, so the benchmark will assign more seats to one party than to the other. This is the partisan bias of the natural benchmark at a tied election, and it is also the portion of the total bias that is not due to the artificial drawing of biased maps.

I compute the partisan bias of the benchmark at a tied election by constructing a hybrid (mathematically, a convex combination) between the 2012 and 2016 elections, such that in this synthetic election, the two-party vote share in the 42 states I study is exactly $50 \%$ for each of the two main parties. In this synthetic tied election, the jurisdiction-based benchmark assigns 203.3 seats to the GOP, and 197.7 to the Democratic party, out of the 401 seats in these states. Thus, the GOP earns according to the benchmark 2.8 additional seats, relative to an even split. In contrast, according to the maps in use, in this synthetic tied election the seat outcomes would be 220 for the GOP and 181 for the Democratic Party, that is, the GOP would obtain 19.5 more than an even split. Since only 2.8 seats of this seat advantage would also hold under apportioning of seats given exogenous jurisdictional lines, the difference of 16.7 seats is artificially obtained through biased redistricting. Therefore, I estimate that approximately $86 \%$ of the seat advantage (or partisan bias) that favors the GOP is an artificial advantage obtained through drawing biased redistricting maps, with only $14 \%$ due to natural factors such as geographic sorting of voters.

Therefore, we expect the magnitude of the artificial partisan advantage to be slightly smaller than, but similar to, the partisan advantage calculated according to notions -such as the partisan bias 
or the efficiency gap- that include every source of partisan asymmetry. Using partisan bias, the efficiency gap, and the mean-median difference, and looking only at 26 states with at least 6 congressional seats, Royden and Li (2017) conclude that "Republicans derive a net benefit of at least 16-17 congressional seats" in these states across the 2012, 2014 and 2016 elections. They note that "residential sorting almost certainly does contribute to partisan bias" but they argue that this sorting is "unlikely" to explain the worst biases. Measuring the Artificial Partisan Advantage allows us to quantify how much of the bias is explained by sorting.

These aggregate patterns are indicative of the magnitude of the artificial partisan advantage, but redistricting is conducted independently by each State, and for evidence of partisan gerrymandering we must look at each state independently.

In Tables A.4-A.7 in the Appendix I show the artificial partisan advantage in each election from 2012 to 2018 for each state. These tables report for each state: the size of the state's delegation; the fraction of the two-party vote obtained by the Republican party; the total population in counties won by Republicans and Democrats; the number of seats that accrue to the Republican party according to the jurisdiction-based seat benchmark; the number of seats that the Republican party actually won; and in the last column, the artificial partisan advantage as the difference between the preceding two columns (negative numbers correspond to an artificial partisan advantage for the Democratic party). ${ }^{23}$

\footnotetext{
${ }^{23}$ As shown in Table A.8, the measures of artificial partisan advantage for the individual states are highly correlated across elections.
} 
Because the absolute magnitude of the partisan advantage correlates with a state's size, I compare the results across states using a notion of excess advantage that is relative to the state's size. Since the benchmark seat allocation based on county lines is fractional, and actual seat outcomes are integers, the smallest possible artificial partisan advantage is the difference between the benchmark and the nearest integer, which can be as large as 0.5 seats. Therefore, I allow a rounding margin of 0.5 seats and I define the excess advantage as the artificial advantage in excess of this rounding margin, divided by the size of the state's delegation.

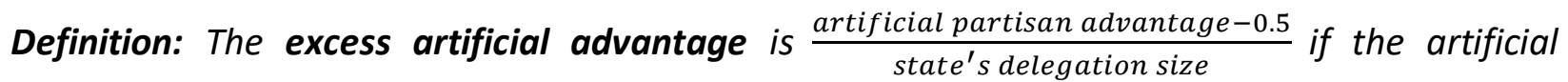
partisan advantage is over 0.5 seats, and zero otherwise.

Averaging across all four elections, the encouraging finding is that twenty one states feature zero excess advantage. Other states have an excess advantage, typically favoring the party that controlled the map-drawing. I highlight the greatest offenders in Table 1, noting their partisan advantage and the size of their state's delegation.

TABLE 1. STATES WITH GREATEST EXCESS ARTIFICIAL PARTISAN ADVANTAGE, 2012-2018. ${ }^{24}$

\begin{tabular}{|c|c|c|c|c|c|c|}
\hline $\begin{array}{c}\text { Excess } \\
\text { advantage, } \\
\text { and size }\end{array}$ & $\begin{array}{c}\text { Artificial } \\
\text { partisan } \\
\text { Advantage }\end{array}$ & $\begin{array}{c}\text { Democratic } \\
\text { Advantage }\end{array}$ & $\begin{array}{c}\text { Republican } \\
\text { Advantage }\end{array}$ & $\begin{array}{c}\text { Artificial } \\
\text { partisan } \\
\text { advantage }\end{array}$ & $\begin{array}{l}\text { Excess } \\
\text { advantage, } \\
\text { and size }\end{array}$ \\
\hline & & & $\begin{array}{c}\text { North Carolina '16-'18 } \\
\text { North Carolina'12-'18 }\end{array}$ & $\begin{array}{c}3.20 \\
2.87\end{array}$ & $\begin{array}{c}20.7 \% \text { of } 13 \\
18.2 \% \text { of } 13\end{array}$ \\
\hline & & & Utah & 1.05 & $13.7 \%$ of 4 \\
\hline & & & Michigan & 1.96 & $10.4 \%$ of 14 \\
\hline $9.8 \%$ of 8 & 1.29 & Maryland & Ohio & 2.15 & $10.3 \%$ of 16 \\
\hline
\end{tabular}

${ }^{24}$ In 2016-18 North Carolina used a remedial map based on its 2012-14 map. 
In Table A.9 in the Appendix I provide the average excess artificial partisan advantage for each state.

As a robustness check, I also compute the measure of artificial partisan advantage in 2012 and 2016 using the election results from the 2012 and 2016 US Presidential elections, instead of the results in the elections to the US House of Representatives. I drop Illinois and Utah, home states of the Democratic and Republican 2012 presidential candidates, because the home-state bias in voting makes the vote in the presidential election not a meaningful proxy for a hypothetical House election. On the other hand, I can add Florida, which was contested by both presidential candidates. The aggregate result across the 40 states included in both methods (all but Florida, Illinois and Utah) is similar for 2012: 28 seats of artificial partisan advantage for the GOP using the House election results, 29 seats using the Presidential election results. In 2016, the artificial partisan advantage for the GOP is greater with the Presidential election results: 26 seats instead of 17.

State by state, there is a strong correlation between the average artificial partisan advantage computed using results from the two Presidential elections or from the two US House ones for 2012 and 2016: the Pearson correlation coefficient is greater than 0.89 . The states with greatest excess advantage are North Carolina, Ohio, Michigan and Pennsylvania. North Carolina, Ohio and Michigan feature an excess average artificial advantage greater than $15 \%$ using either pair of election results; Pennsylvania shows an $18 \%$ excess average artificial advantage using the Presidential elections results, 
and $10 \%$ using the congressional ones. ${ }^{25} \mathrm{I}$ report the artificial partisan advantage and the excess advantage in each state using the 2012 and 2016 Presidential election result in Table A.10.

\section{COMPARISON TO OTHER MEASURES OF PARTISAN ADVANTAGE}

I discuss five alternative measures of partisan advantage in redistricting: partisan bias; the median-mean difference; the declination; the efficiency gap; and the location of the actual map in a distribution over simulated maps. I relate the artificial partisan advantage to these measures.

\subsection{Partisan bias.}

The notion of partisan bias measures asymmetries in how parties convert votes to seats. For each of two main parties $A$ and $B$, (and holding constant the votes for minority parties), we construct the party's "vote-to-seats" curve by mapping the number of seats that the party obtains if it gets fraction $x$ of the two-party vote, for each $x$ between 0 and 1 . The partisan bias is a pointwise measure: the partisan bias in favor of $A$ at vote share $x$ is the difference between the number of seats that Party $A$ obtains if it gets a fraction $x$ of the two party votes, and the number of seats that Party $B$ obtains if $B$ gets fraction $x$ of votes (Butler 1951 and 1952). From the pointwise measure, we can obtain a global axiom: partisan symmetry holds if the partisan bias is zero for any vote share $x$, so that the two vote-to-seats curves are equal (Tufte 1973; Grofman 1983; King and Browning 1987).

\footnotetext{
25 Incidentally, this 2012-2016 redistricting map of Pennsylvania was struck down as an unconstitutional partisan gerrymander by the Supreme Court of Pennsylvania, in League of Women Voters of Pennsylvania v. Commonwealth of Pennsylvania 178 A.3d 737 (2018).
} 
Given a probability measure over possible vote splits, we can integrate the difference between the two vote-to-seat curves weighed by this probability measure. The resulting measure of global partisan bias is the expectation over the pointwise bias (Katz, King and Rosenblatt 2020).

To compute the partisan bias, we must estimate counterfactual seat outcomes given counterfactual vote shares. The standard approach is to start with the actual vote share, and to assume a uniform swing across all districts in the magnitude appropriate to generate the desired counterfactual vote share. The estimate of partisan bias therefore relies on hypothetical voting profiles. In states with lopsided election results, this counterfactual is far out of sample: for instance, in 2018 in Maryland the Democrat vs GOP two-party vote share split was 67\% to 33\%, and our measure of partisan bias relies on our estimate of the seat outcome given a counterfactual vote share split of $33 \%$ to $67 \%$, a $34 \%$ swing. Courts have expressed reluctance toward relying on such counterfactuals. Quoting from SCOTUS's Opinion of the Court in LULAC (2006): “we are wary of adopting a constitutional standard that invalidates a map based on unfair results that would occur in a hypothetical state of affairs." ${ }^{26}$ Nevertheless, partisan bias remains the most prominent notion of partisan advantage in the academic literature. ${ }^{27}$

The notion of partisan bias measures any deviation from symmetry across parties in the mapping from vote shares to seats. It does not examine the causes or mechanisms that generate this deviation. In particular, the notion of partisan bias does not distinguish whether the

\footnotetext{
${ }^{26}$ Justice Kennedy's Opinion of the Court in LULAC v. Perry, 548 U.S. 399, 420 (2006).

27 See for instance influential work by Cox and Katz (1999) or Grofman and King (2007), among others.
} 
asymmetry is due to the redistricting maps, or to other factors such as the geographical distribution of each party's voters.

If the distribution is asymmetric due to geographic sorting of voters, then the existence of a partisan bias does not indicate that the redistricting maps are flawed (see Justice Scalia's quote above; footnote 4). In the words of Justice Kennedy's Opinion of the Court in LULAC (2006), because "the existence or degree of asymmetry may in large part depend on conjecture about where possible vote-switchers will reside" [...] "asymmetry alone is not a reliable measure of unconstitutional partisanship."28

Consider the following example.

Example 1. A State consists of three islands, each of them its own county, named Left I., Center I., and Right I., and with the following distribution of votes:

\begin{tabular}{|c|c|c|c|c|}
\hline & Left Island & Center Island & Right Island & Total \\
\hline Party A & $90 \%$ & $30 \%$ & $30 \%$ & $50 \%$ \\
\hline Party B & $10 \%$ & $70 \%$ & $70 \%$ & $50 \%$ \\
\hline
\end{tabular}

If each island constitutes its own district, Party A wins one district, and Party B wins two; a large partisan bias, but with zero artificial partisan advantage. The asymmetry in this case is not due to an artificial drawing of districts, but due to the sorting of voters across the three islands. To attain party symmetry, we would need to artificially gerrymander cross-island districts in favor of Party A.

Whereas the partisan bias measures the total partisan advantage that a party enjoys in its mapping from voting profiles to seats, without distinguishing the factors that contribute to this

${ }^{28}$ Justice Kennedy's Opinion of the Court in LULAC v. Perry, 548 U.S. 399, 420 (2006). 
advantage, the artificial partisan advantage measures the partisan advantage net of the natural advantage due to geographical sorting of voters, so it captures only the partisanship or bias that accrues to a party due to the redistricting maps in use.

As I discussed in the previous section, the two measures can be used together to measure the natural advantage due to sorting, by subtracting the artificial partisan advantage (net advantage) from the partisan bias (total advantage).

\subsection{Other measures of asymmetry: median-mean difference, efficiency gap, and declination}

The Supreme Court's objections to the reliance on counterfactuals (see quote above in subsection A3.1) spurred an interest in measures that only use actual voting results.

The first of these is the difference between the mean vote share in the state, and the vote share in the median district, shortened to "median-mean" difference. As noted as far back as Edgeworth (1898), one may think that this difference should be zero. Butler (1951 and 1952) finds that in the UK elections of 1950 and 1951 it was not zero; in fact, in 1951 Labour obtained a higher mean vote share, and yet the Tory party won the median district. Erikson (1972) identifies a similar phenomenon in the United States, and he refers to this pattern of large wins for Democrats in urban districts, and smaller wins for Republicans elsewhere as "accidental gerrymanders" that favour the Republican Party. ${ }^{29}$

McDonald and Best (2015) note that we can identify partisan gerrymanders by finding the states with a large median-mean vote difference. Gerrymandering affects the median-mean difference because it leaves the mean vote across the state unchanged, but by changing the

${ }^{29}$ On the urban/rural divide and its effects on redistricting, see as well Rodden (2019). 
composition of districts, it can elevate the vote share of a favored party in the median district, generating a positive difference between median and mean. However, since this difference can also arise accidentally with neutral maps through the residential patterns of voters, "in order to distinguish unintentional from intentional gerrymanders, a benchmark of what naturally would result from any neutral line drawing has to be established."

This is the same motivation underpinning the notion of an artificial partisan advantage: to compute asymmetries net of the effects of the geographic sorting of voters, by resorting to a "natural" benchmark. For instance, in Example 1 above, the vote for Party $B$ in the median district is $70 \%$, while the party's mean vote is $50 \%$, so the difference is $20 \%$, but this difference is entirely natural, due to the distribution of voters across islands, so this would be an unintentional or accidental gerrymander.

The median-mean difference is arguably a more relevant measure in closely contested states in which either party can win a majority of districts under some map. It is less informative in states with one dominant party. In these states, the median district will not be competitive under any map, and partisan gerrymandering will focus on the few competitive districts in the state.

More recently, Warrington (2018) proposed a new measure of asymmetries in the distribution actual results across districts is the declination (Warrington 2018). The "declination" measures whether there is a discontinuity in the distribution of results at $50 \%$ vote share. This discontinuity would be anomalous if districts were naturally drawn, but it will happen by design if districts are gerrymandered. ${ }^{30}$

\footnotetext{
${ }^{30}$ See Wang (2016) as well for other tests of symmetry in the distribution of votes across districts.
} 
The most influential of the new measures of partisan advantage in redistricting developed in the past few years is the "efficiency gap" (McGhee 2014; Stephanopoulos and McGhee 2015; Stephanopoulos and McGhee 2018). ${ }^{31}$ This measure compares the ability of each party to translate votes to seats, by computing the number of votes for each party that are "wasted." Wasted votes are those cast for a losing candidate, or for a winning candidate in excess of the number of votes necessary to win.

The efficiency gap is the difference in this share of wasted votes for each party. With equal turnout across constituencies, the efficiency gap simplifies: it is the difference between the seat share in excess of $50 \%$ for the largest party, and the vote share margin. That is, zero gap requires party symmetry and a slope of two in the conversion of votes to seats.

Nevertheless, the efficiency gap has elicited criticism (Chambers, Miller and Sobel 2017; Bernstein and Duchin 2017; Katz, King and Rosenblatt 2020; Rush 2020). I highlight one limitation: because in uncontested races the winner gets all votes, it wastes half of them, inducing the measure to identify the map as gerrymandered against winners of uncontested races. ${ }^{32}$ The artificial partisan advantage does not face these problems: one can compare actual results to the

${ }^{31}$ A 2018 amendment to the Missouri Constitution enshrined the efficiency gap as the constitutional measure of partisan fairness in redistricting in this state.

${ }^{32}$ Attempts to remedy this problem by imputing the electoral result that would have occurred had the race been contested, using either previous results, or up- or down- ballot results, reintroduce the problem of reliance on counterfactuals, rather than on actual results for the seat in question. 
jurisdiction-based benchmark result in any state that tallies election results, even if these results are lopsided or uncontested.

The efficiency gap, the mean-median difference and the partisan bias are measures of partisan asymmetry in the mapping from votes to seats, regardless of the cause of this asymmetry. Whereas, the artificial partisan advantage is a measure of the asymmetry introduced specifically by the redistricting maps.

\subsection{Outlier test}

The artificial partisan advantage is closer in spirit to the computational approach of Chen and Rodden (2013 and 2015), Chen and Cottrell (2016), Cho and Liu (2016), Duchin (2018), Cho (2019) and others. This approach also seeks to measure the partisan advantage that is attributable specifically to a given redistricting map, and not to the geographic distribution of voters. Instead of assessing the fairness of a given map by comparing the seat outcomes under this map to those under a "natural" benchmark map, it compares the actual seat outcome against the distribution of outcomes under a large sample of alternative possible maps, computationally simulated from a pool of admissible maps.

By drawing a large distribution of maps, and hence of outcomes, this computational approach can compare the actual seat outcome to the distribution of possible outcomes. If the actual seat outcome is extreme, at the tail of the distribution of outcomes according to simulated maps, we can regard the current map as a partisan gerrymander.

This approach is compelling, with a couple technical caveats. First, it is difficult to define the set of admissible maps from which to draw simulated maps. Say we determine that in order 
to be admissible, maps ought to be somewhat compact: how compact? ${ }^{33}$ If admissible maps ought to satisfy the Voting Rights Acts (VRA) minority protections, then to determine if a map is included, we'll first need to determine its compliance with the VRA, which in some cases is controversial. Once we overcome (or put aside) this caveat, and we settle on a set of admissible maps, a second problem emerges: it is difficult to devise a truly random algorithm to draw a sample from the set of admissible maps. See Katz, King and Rosenblatt (2020) for a discussion of these challenges.

The artificial partisan advantage resolves both problems resorting to simplicity: instead of comparing the actual outcome to the distribution of outcomes from a (hard to draw) random sample out of a (hard to define) set of admissible maps, it compares the actual outcome to one, easy to compute seat benchmark: the seat outcome that would emerge if we bypassed districting altogether, and we instead apportioned seats according to the state's exogenously given jurisdictions such as counties, and also cities and townships in large counties.

The computational approach and the artificial partisan advantage can be used in conjunction with each other: if we create a distribution of outcomes according to a large sample of maps, we can place the outcome according to the county-based benchmark in this distribution, so that we learn how extreme is the benchmark we use to compute the artificial partisan advantage.

33 On compactness, see Chambers and Miller (2010), and Saxon (2018). Saxon proposes to compare the actual seat outcome to the one with the most compact map. 
A pragmatic map-drawer may wish to compute many or all these measures, together with the artificial partisan advantage, for any proposed plan. Ideally, the selected map will perform well according to all measures; if it performs well in some and poorly in others, we can use this information to evaluate the merits of the plan; if it performs poorly in the measures deemed more compelling by the map-drawer, the map should be redrawn.

State courts evaluating the partisan fairness of a given maps must first answer the normative question posed by Chief Justice Roberts in the ruling in Rucho v. Common Cause (2019): "Should a court 'reverse gerrymander' other parts of a State to counteract 'natural' gerrymandering caused, for example, by the urban concentration of one party?" 34

Should "partisan fairness" measure the total, absolute partisan advantage regardless of its source? or should it measure instead the advantage that is due specifically to the redistricting map, net of any natural advantage due to other factors such as the geographic sorting of voters or differential turnout rates?

If we consider that a map should fully compensate any natural advantage that accrues to a party due to geographic sorting by drawing maps that help the opposite party ("reverse gerrymandering") so as to cancel out this advantage, then we should strive for partisan symmetry. Whereas, if we consider that a redistricting map is "fair" if it does not introduce any partisan advantage, then I suggest we should strive to minimize the artificial partisan advantage.

\footnotetext{
${ }^{34}$ Rucho v Common Cause 139 S. Ct. 2484, 2501 (2019).
} 


\section{CONCLUSION}

I have proposed a measure of artificial partisan advantage in redistricting that is based on existing jurisdictional lines such as counties and townships. This notion measures the partisan advantage that is due specifically to the way the redistricting maps are drawn, and not due to geographic sorting of the voting population. I find that the aggregate artificial partisan advantage for the Republican party in the past four elections to the US House is seventeen seats.

State by state, I find that the congressional district maps in North Carolina, Utah, Michigan, Ohio and Maryland exhibit the greatest excess of artificial partisan advantage. An in-depth discussion of the properties and limitations of the measure of artificial partisan advantage, and detailed state-by-state results, are available in an online appendix.

The immediate purpose of the artificial partisan advantage measure is to serve as a tool to identify which redistricting maps generate a partisan advantage, so that legislators and commissioners can draw neutral maps, and Courts can strike down partisan gerrymanders more confidently if these are drawn. The ultimate goal is to contribute to run elections with a fairer representation of the citizenry's preferences. 


\section{APPENDIX}

TABLE A.1. STATES' LEGAL RESTRICTIONS AGAINST PARTISAN ADVANTAGE IN REDISTRICTING.

i. California: Districts cannot be drawn with the purpose of favoring or discriminating against any candidate (CAL. CONST. art. XXI, § 2(e)).

ii. Colorado. Districts cannot be drawn to protect incumbent members, candidates, or any political party (COLO. CONST. art V, § 48.1(4)(a)).

iii. Delaware. Districts may not "unduly favor any person or political party" (DEL. CODE § 29.805).

iv. Florida. No favoritism towards incumbent or party (FLA. CONST. art. III, § 21(a)).

v. Hawaii. No favoritism towards a person or political faction (HAW. CONST. art. IV, § 6).

vi. Idaho. Counties cannot be divided to protect a party (IDAHO statute $72.1506(08)$ ).

vii. lowa. No favoritism towards any person, party, or group (IOWA CODE § 42.4(5)).

viii. Michigan. No disproportionate advantage to any political party, according to "accepted measures of partisan fairness" (MICH. CONST. art. IV, § 6(13)(d)).

ix. Missouri. The efficiency gap must be close to zero (MISSOURI CONST. art. III, §3).

x. Montana. Cannot favor a political party or incumbent (MONT. CODE ANN. § 5-1-115(3)).

xi. New York. Cannot favor incumbents, candidates, or parties (N.Y.CONST. art. III, § 4(c)(5)).

xii. Ohio. A map passed with a simple majority shall not be drawn primarily to favor or disfavor a political party (OHIO CONST. art. XI, § 6(A)).

xiii. Oregon. No purposeful favoritism towards person or party (OREGON Code 188.010).

xiv. Washington. Districts shall not purposefully favour a political party (WASH. CONST. art. II, $§ 43(5))$. 
TABLE A.2. ARTIFICIAL PARTISAN ADVANTAGE IN NEW HAMPSHIRE, 2018.

\begin{tabular}{|c|c|c|c|c|c|}
\hline \multirow[b]{2}{*}{ County Name } & \multirow[b]{2}{*}{ [1] Pop } & \multirow[b]{2}{*}{ [2] D Vote } & \multirow[b]{2}{*}{ [3] R Vote } & \multicolumn{2}{|c|}{ Pop. counties won by } \\
\hline & & & & [4] Dem & [5] Rep \\
\hline Belknap & 60,088 & 12,256 & 14,125 & 0 & 60,088 \\
\hline Carroll & 47,818 & 12,146 & 11,464 & 47,818 & 0 \\
\hline Cheshire & 77,117 & 19,784 & 11,830 & 77,117 & 0 \\
\hline Coos & 33,055 & 6,008 & 4,971 & 33,055 & 0 \\
\hline Grafton & 89,118 & 25,627 & 13,499 & 89,118 & 0 \\
\hline Hillsborough & 400,721 & 86,961 & 70,877 & 400,721 & 0 \\
\hline Merrimack & 146,445 & 36,702 & 26,626 & 146,445 & 0 \\
\hline Rockingham & 295,223 & 71,211 & 66,089 & 295,223 & 0 \\
\hline Strafford & 123,143 & 30,819 & 21,469 & 123,143 & 0 \\
\hline Sullivan & 43,742 & 9,200 & 7,553 & 43,742 & 0 \\
\hline N. HAMPSHIRE & $1,316,470$ & 311,242 & 248,986 & $1,256,382$ & 60,088 \\
\hline & & & & $95.44 \%$ & $4.56 \%$ \\
\hline & & & Benchmark & 1.91 & 0.09 \\
\hline & & & Total Seats & 2.00 & 0.00 \\
\hline & Artifi & ial Partisan & Advantage & 0.09 & -0.09 \\
\hline
\end{tabular}

Table A.2. demonstrates the procedure to compute the artificial partisan advantage. New Hampshire has two congressional districts. For each county, column [1] indicates the population of the county; column [2] is the popular vote for the Democratic party in the county, aggregated across all races for US House seats in the county; column [3] is the analogous popular vote for the Republican party in the county. In counties in which the Democratic party candidates got more votes $([2]>[3])$, the population of the county is assigned to the Democratic column [4], whereas if the Republican party got more votes $([3]>[2])$, the county population goes to the Republican column [5]. Adding up across counties, we get the state totals. We find that $95.4 \%$ of the population is in counties won by the Democratic candidates, and $4.6 \%$ in counties won by the Republicans. So the number of seats for the Democratic party according to the county-based benchmark natural seat benchmark is $95.4 \%$ of 2 seats, that is, 1.91 seats. Since the Democratic party obtained both New Hampshire seats, the artificial partisan advantage is $2.00-1.91=0.09$.

Data sources: The data for column [1] is from the US Census at www.census.gov. The data for columns [2] and [3] is from the New Hampshire Secretary of State at sos.nh.gov/18GenResults.aspx. Columns [4] and [5] are computed from the first three columns. 
TABLE A.3. LARGE COUNTIES SPLIT INTO SMALLER JURISDICTIONAL UNITS.

In bold, the original counties; underneath, the jurisdictional units I use.

\begin{tabular}{|c|c|}
\hline County name & Population \\
\hline Los Angeles County, California & $9,818,000$ \\
\hline City of Los Angeles & $3,792,621$ \\
\hline City of Long Beach & 462,257 \\
\hline City of Santa Clarita & 210,888 \\
\hline City of Glendale & 203,054 \\
\hline City of Lancaster & 160,316 \\
\hline City of Palmdale & 152,750 \\
\hline City of Pomona & 149,058 \\
\hline City of Torrance & 145,438 \\
\hline City of Pasadena & 137,122 \\
\hline City of El Monte & 113,475 \\
\hline City of Downey & 111,772 \\
\hline City of Inglewood & 109,673 \\
\hline City of West Covina & 106,098 \\
\hline City of Norwalk & 105,549 \\
\hline City of Burbank & 103,340 \\
\hline City of Compton & 96,455 \\
\hline City of South Gate & 94,396 \\
\hline City of Carson & 91,714 \\
\hline City of Santa Monica & 89,736 \\
\hline City of Whittier & 85,331 \\
\hline City of Hawthorne & 84,293 \\
\hline City of Alhambra & 83,653 \\
\hline City of Lakewood & 80,048 \\
\hline City of Bellflower & 76,616 \\
\hline City of Baldwin Park & 75,390 \\
\hline City of Lynwood & 69,772 \\
\hline City of Redondo Beach & 66,748 \\
\hline City of Pico Rivera & 62,942 \\
\hline City of Montebello & 62,500 \\
\hline City of Monterey Park & 60,269 \\
\hline City of Gardena & 58,829 \\
\hline City of Huntington Park & 58,114 \\
\hline City of Arcadia & 56,364 \\
\hline City of Diamond Bar & 55,544 \\
\hline City of Paramount & 54,098 \\
\hline City of Rosemead & 53,764 \\
\hline City of Glendora & 50,073 \\
\hline City of Cerritos & 49,041 \\
\hline
\end{tabular}


City of La Mirada

48,527

City of Covina

47,796

City of Azusa

46,361

City of Bell Gardens

42,072

City of Rancho Palos Verdes

41,643

City of La Puente

39,816

City of San Gabriel

39,718

Culver City

38,883

City of Monrovia

36,590

Temple City

35,558

City of Bell

35,477

City of Manhattan Beach

35,135

City of Claremont

34,926

City of West Hollywood

34,399

City of Beverly Hills

34,109

City of San Dimas

33,371

City of Lawndale

32,769

City of La Verne

31,063

City of Walnut

29,172

City of Maywood

27,395

Rest of LA County

$1,394,724$

\section{Cook County, Illinois}

City of Chicago

Thornton township

Wheeling township

Worth township

Proviso township

Maine township

Schaumburg township

$\mathbf{5 , 1 9 4 , 6 7 5}$

$2,695,598$

169,326

153,630

152,633

151,704

135,772

131,288

Palatine township

112,994

Lyons township

111,688

Rest of Cook County

$1,380,042$ 
Harris County, Texas ${ }^{35}$

City of Houston

City of Pasadena

City of Baytown

City of Atascocita

City of Spring

City of Channelview

City of La Porte

City of Deer Park

City of Cloverleaf

City of South Houston

City of Bellaire

City of Aldine

City of Humble

City of West University Place

City of Mission Bend

City of Seabrook

City of Katy

City of Galena Park

City of Tomball

Jacinto City

City of Webster

City of Friendswood

City of Jersey Village

Rest of Harris County

Maricopa County, Arizona

City of Phoenix

City of Mesa

City of Chandler

City of Glendale

City of Scottsdale

Rest of Maricopa County

San Diego County, California

City of San Diego
4,092,459

$2,057,280$

149,043

67,686

65,844

54,298

38,289

33,800

32,010

22,942

16,893

16,855

15,869

15,133

14,787

12,416

11,952

11,278

10,887

10,753

10,553

10,400

10,295

7,620

$1,395,486$

$3,817,117$

$1,445,632$

439,041

236,123

226,721

217,385

$1,252,215$

$3,095,313$

$1,307,402$

35 To obtain election results at the city level in Harris County, I use geographic data from GeoCorr 2014 from the Missouri Census Data Center. In all other counties that do not provide results by city, I aggregate precinct results according to the US Post Service address of the precinct ballot. In Harris county, the US Post Service and the Census maps of jurisdictions diverge greatly. 
City of Chula Vista

243,916

City of Oceanside

167,086

Rest of San Diego County

$1,376,909$

Orange County, California

3,010,232

City of Anaheim

336,265

City of Santa Ana

324,528

City of Irvine

212,375

City of Huntington Beach

191,037

City of Garden Grove

170,883

136,416

135,161

109,960

City of Costa Mesa

$1,393,607$

Dallas County, Texas

2,368,139

City of Dallas

$1,197,816$

Rest of Dallas County

1,170323

Riverside County, California

2,189,641

City of Riverside

303,871

City of Moreno Valley

193,365

City of Corona

152,374

103,466

100,097

City of Temecula

$1,336,468$

San Bernardino County, California

$2,035,210$

City of San Bernardino

209,924

City of Fontana

196,069

165,269

163,924

City of Ontario

$1,300,024$

Rest of San Bernardino County

$1,951,269$

Clark County, Las Vegas

583,756

257,729

City of Henderson

$1,109,784$

Rest of Clark County

$1,931,249$

King County, Washington

608,660

City of Seattle

$1,322,589$ 
Wayne County, Michigan

City of Detroit

Rest of Wayne County

Tarrant County, Texas

City of Fort Worth

Rest of Tarrant County

Santa Clara County, California

City of San Jose

Rest of Santa Clara County

Bexar County, Texas

City of San Antonio

Rest of Bexar County

Alameda County, California

City of Oakland

Rest of Alameda County

Middlesex County, Massachusetts

City of Lowell

Rest of Middlesex County

Suffolk County, New York

Town of Brookhaven

Rest of Suffolk County

Sacramento County, California

City of Sacramento

Rest of Sacramento County
$1,820,584$

713,777

$1,106,807$

$1,809,034$

726,815

$1,082,219$

1,781,642

945,942

835,700

$1,714,773$

$1,327,407$

387,366

1,510,271

390,724

$1,119,547$

$1,503,085$

106,519

$1,396,566$

$1,493,350$

486,040

$1,007,310$

$1,418,788$

466,488

952,300 
TABLE A.4. ARTIFICIAL PARTISAN ADVANTAGE BY STATE, 2012 US HOUSE ELECTION

\begin{tabular}{|c|c|c|c|c|c|c|c|}
\hline \multirow{3}{*}{$\begin{array}{l}\text { State } \\
\text { Alabama }\end{array}$} & \multirow[b]{2}{*}{ [1] Seats } & \multirow[b]{2}{*}{ [2] $R$ vote } & \multicolumn{2}{|c|}{ Pop. in counties won } & \multicolumn{2}{|c|}{ Republican Seats } & \multirow{2}{*}{ [7] Art. Adv. } \\
\hline & & & [3] by $R$ & [4] by D & [5] Earned & [6] Total & \\
\hline & 7 & $64.0 \%$ & $3,595,329$ & $1,184,407$ & 5.27 & 6 & 0.73 \\
\hline Arizona & 9 & $54.4 \%$ & $3,596,877$ & $2,795,140$ & 5.06 & 4 & -1.06 \\
\hline Arkansas & 4 & $67.7 \%$ & $2,209,724$ & 706,194 & 3.03 & 4 & 0.97 \\
\hline California $^{36}$ & 53 & $38.0 \%$ & $12,044,599$ & $25,065,831$ & 17.14 & 15 & -2.14 \\
\hline Colorado & 7 & $51.4 \%$ & $1,807,042$ & $3,222,154$ & 2.52 & 4 & 1.48 \\
\hline Connecticut & 5 & $34.5 \%$ & 189,927 & $3,384,170$ & 0.27 & 0 & -0.27 \\
\hline Georgia & 14 & $59.2 \%$ & $6,456,539$ & $3,231,114$ & 9.33 & 9 & -0.33 \\
\hline Hawaii & 2 & $32.5 \%$ & 0 & $1,360,211$ & 0 & 0 & 0.00 \\
\hline Idaho & 2 & $66.1 \%$ & $1,508,962$ & 58,620 & 1.93 & 2 & 0.07 \\
\hline Illinois & 18 & $44.6 \%$ & $7,021,234$ & $5,809,398$ & 9.85 & 6 & -3.85 \\
\hline Indiana & 9 & $54.2 \%$ & $3,931,252$ & $2,552,550$ & 5.46 & 7 & 1.54 \\
\hline lowa & 4 & $48.5 \%$ & $1,028,392$ & $2,017,963$ & 1.35 & 2 & 0.65 \\
\hline Kansas & 4 & $79.1 \%$ & $2,564,358$ & 288,760 & 3.60 & 4 & 0.40 \\
\hline Kentucky & 6 & $60.0 \%$ & $3,214,700$ & $1,124,667$ & 4.44 & 5 & 0.56 \\
\hline Louisiana & 6 & $77.4 \%$ & $4,088,130$ & 445,242 & 5.41 & 5 & -0.41 \\
\hline Maine & 2 & $38.3 \%$ & 32,856 & $1,295,505$ & 0.05 & 0 & -0.05 \\
\hline Maryland & 8 & $34.5 \%$ & $1,199,765$ & $4,573,797$ & 1.66 & 1 & -0.66 \\
\hline Massachusetts & 9 & $25.1 \%$ & 0 & $6,547,629$ & 0 & 0 & 0.00 \\
\hline Michigan & 14 & $47.3 \%$ & $3,894,720$ & $5,988,920$ & 5.52 & 9 & 3.48 \\
\hline Minnesota & 8 & $43.7 \%$ & $1,233,278$ & $4,070,647$ & 1.86 & 3 & 1.14 \\
\hline Mississippi & 4 & $63.1 \%$ & $2,176,730$ & 790,567 & 2.93 & 3 & 0.07 \\
\hline Missouri & 8 & $56.7 \%$ & $3,810,509$ & $2,178,418$ & 5.09 & 6 & 0.91 \\
\hline Nebraska & 3 & $64.2 \%$ & $1,309,231$ & 517,110 & 2.15 & 3 & 0.85 \\
\hline Nevada & 4 & $50.2 \%$ & $1,007,011$ & $1,693,540$ & 1.49 & 2 & 0.51 \\
\hline
\end{tabular}

\footnotetext{
${ }^{36}$ An Independent won the cities of Redondo Beach, Rancho Palos Verdes and Manhattan Beach in Los Angeles County, earning 0.20 seats.
} 


\begin{tabular}{|c|c|c|c|c|c|c|c|}
\hline N. Hampshire & 2 & $47.8 \%$ & 756,032 & 560,438 & 1.15 & 0 & -1.15 \\
\hline New Jersey & 12 & $44.4 \%$ & $3,003,768$ & $5,788,126$ & 4.10 & 6 & 1.90 \\
\hline New Mexico & 3 & $44.8 \%$ & 666,801 & $1,392,378$ & 0.97 & 1 & 0.03 \\
\hline New York & 27 & $35.1 \%$ & $2,960,613$ & $16,417,489$ & 4.13 & 6 & 1.87 \\
\hline North Carolina & 13 & $49.1 \%$ & $4,253,681$ & $5,281,802$ & 5.80 & 9 & 3.20 \\
\hline Ohio & 16 & $52.1 \%$ & $6,274,156$ & $5,262,348$ & 8.70 & 12 & 3.30 \\
\hline Oklahoma & 5 & $67.6 \%$ & $3,751,351$ & 0 & 5 & 5 & 0 \\
\hline Oregon & 5 & $42.0 \%$ & $1,042,096$ & $2,788,978$ & 1.36 & 1 & -0.36 \\
\hline Pennsylvania & 18 & $49.2 \%$ & $6,909,453$ & $5,792,926$ & 9.79 & 13 & 3.21 \\
\hline Rhode Island & 2 & $41.0 \%$ & 49,875 & $1,002,692$ & 0.09 & 0 & -0.09 \\
\hline South Carolina & 7 & $58.0 \%$ & $3,108,788$ & $1,516,576$ & 4.70 & 6 & 1.30 \\
\hline Tennessee & 9 & $63.2 \%$ & $4,669,785$ & $1,676,320$ & 6.62 & 7 & 0.38 \\
\hline Texas & 36 & $60.0 \%$ & $15,099,489$ & $10,046,072$ & 21.62 & 24 & 2.38 \\
\hline Utah & 4 & $66.6 \%$ & $1,697,906$ & $1,065,979$ & 2.46 & 3 & 0.54 \\
\hline Virginia & 11 & $51.0 \%$ & $4,287,965$ & $3,713,059$ & 5.90 & 8 & 2.10 \\
\hline Washington & 10 & $45.6 \%$ & $2,134,246$ & $4,590,294$ & 3.17 & 4 & 0.83 \\
\hline West Virginia & 3 & $59.9 \%$ & $1,391,478$ & 461,516 & 2.25 & 2 & -0.25 \\
\hline Wisconsin & 8 & $49.2 \%$ & $2,939,822$ & $2,747,164$ & 4.14 & 5 & 0.86 \\
\hline TOTAL & 401 & & $132,918,460$ & $151,006,801$ & 187.35 & 212 & 24.65 \\
\hline
\end{tabular}


TABLE A.5. ARTIFICIAL PARTISAN ADVANTAGE BY STATE, 2014 US HOUSE ELECTION

Pop. in counties won

State

Alabama

Arizona $\quad 9$

Arkansas $\quad 4$

California $\quad 53$

Colorado $\quad 7$

Connecticut 5

Georgia $\quad 14$

Hawaii 2

Idaho 2

Illinois $\quad 18$

Indiana $\quad 9$

lowa $\quad 4$

Kansas $\quad 4$

Kentucky 6

Louisiana 6

Maine 2

Maryland 8

Massachusetts 9

Michigan 14

Minnesota 8

Mississippi $^{37} \quad 4$

Missouri 8

Nebraska 3

Nevada 4

N. Hampshire 2

New Jersey

12
[3] by $\mathbf{R}$

$68.0 \%$

$58.6 \%$

$66.7 \%$

$42.0 \%$

$51.6 \%$

$39.6 \%$

$58.5 \%$

$33.8 \%$

$63.2 \%$

$48.6 \%$

$61.2 \%$

$53.9 \%$

$63.4 \%$

$63.6 \%$

$67.6 \%$

$42.8 \%$

$41.9 \%$

$17.3 \%$

$49.1 \%$

$48.1 \%$

$58.9 \%$

$62.0 \%$

$64.8 \%$

$59.2 \%$

$48.4 \%$

$49.0 \%$
[4] by $D$

$3,374,840 \quad 1,404,896$

$3,605,341$

$2,786,703$

$2,212,405$

$14,905,586$

3,003140

189,927

$6,129,354$

0

$1,498,792$

$7,126,914$

4,384,351

$1,504,712$

$2,584,787$

$3,570,599$

$3,468,594$

524,715

$2,078,729$

0

$5,099,155$

$2,227,778$

$2,156,739$

4,995,475

$1,309,231$

$1,590,767$

803,850

$3,292,056$

703,513

$22,348,370$

$2,026,056$

$3,384,170$

$3,558,299$

$1,360,211$

68,790

$5,703,718$

$2,099,451$

$1,541,643$

268,331

768,768

$1,064,778$

803,646

$3,694,823$

$6,547,629$

$4,784,485$

$3,076,147$

799,961

993,452

517,110

$1,109,784$

512,620

$5,499,838$
Republican seats

[5] Earned [6] Total [7] Art.Adv.

4.94

4.94

6

1.06

5.08

3.03

21.21

4.18

0.27

8.86

0.00

1.91

10.00

6.09

1.98

3.62

4.94

4.59

0.79

2.88

0.00

7.22

3.36

2.91

6.67

2.15

2.36

1.22

4.49

6

1.51 


$\begin{array}{lrrrrrrr}\text { New Mexico } & 3 & 47.0 \% & 910,235 & 1,148,944 & 1.33 & 1 & -0.33 \\ \text { New York } & 27 & 43.6 \% & 7,097,521 & 12,280,581 & 9.89 & 9 & -0.89 \\ \text { North Carolina } & 13 & 55.8 \% & 5,952,742 & 3,582,741 & 8.12 & 10 & 1.88 \\ \text { Ohio } & 16 & 60.0 \% & 8,667,173 & 2,869,331 & 12.02 & 12 & -0.02 \\ \text { Oklahoma } & 5 & 72.4 \% & 3,751,351 & 0 & 5.00 & 5 & 0.00 \\ \text { Oregon } & 5 & 42.8 \% & 1,141,289 & 2,689,785 & 1.49 & 1 & -0.49 \\ \text { Pennsylvania } & 18 & 55.5 \% & 8,488,306 & 4,214,073 & 12.03 & 13 & 0.97 \\ \text { Rhode Island } & 2 & 38.9 \% & 0 & 1,052,567 & 0.00 & 0 & 0.00 \\ \text { South Carolina } & 7 & 65.8 \% & 3,739,998 & 885,366 & 5.66 & 6 & 0.34 \\ \text { Tennessee } & 9 & 65.4 \% & 4,791,780 & 1,554,325 & 6.80 & 7 & 0.20 \\ \text { Texas } & 36 & 64.6 \% & 16,691,184 & 8,454,377 & 23.90 & 25 & 1.10 \\ \text { Utah } & 4 & 65.7 \% & 1,697,906 & 1,065,979 & 2.46 & 4 & 1.54 \\ \text { Virginia } & 11 & 57.5 \% & 5,061,958 & 2,939,066 & 6.96 & 8 & 1.04 \\ \text { Washington } & 10 & 48.4 \% & 2,134,246 & 4,590,294 & 3.17 & 4 & 0.83 \\ \text { West Virginia } & 3 & 57.1 \% & 1,491,886 & 361,108 & 2.42 & 3 & 0.58 \\ \text { Wisconsin } & 8 & 52.8 \% & 3,213,336 & 2,473,650 & 4.52 & 5 & 0.48 \\ \text { TOTAL } & 401 & & 156,468,721 & 127,589,469 & 220.49 & 225 & 4.51\end{array}$

${ }^{37}$ An Independent won Carrol county (MS), earning a 0.01 seat benchmark for independents. 
TABLE A.6. ARTIFICIAL PARTISAN ADVANTAGE BY STATE, 2016 US HOUSE ELECTION

\begin{tabular}{|c|c|c|c|c|c|c|c|}
\hline & & & Pop. in co & ties won & Repu & blican & \\
\hline State & [1] Seats & [2] R vote & [3] by $R$ & [4] by D & [5] Earned & [6] Total [ & 7] Art. Adv. \\
\hline Alabama & 7 & $66.3 \%$ & $3,406,840$ & $1,372,896$ & 4.99 & 6 & 1.01 \\
\hline Arizona & 9 & $55.0 \%$ & $3,409,563$ & $2,982,454$ & 4.80 & 5 & 0.20 \\
\hline Arkansas & 4 & $87.2 \%$ & $2,533,170$ & 382,748 & 3.47 & 4 & 0.53 \\
\hline California & 53 & $36.3 \%$ & $10,279,189$ & $26,974,767$ & 14.62 & 14 & -0.62 \\
\hline Colorado & 7 & $50.5 \%$ & $2,547,634$ & $2,481,562$ & 3.55 & 4 & 0.45 \\
\hline Connecticut & 5 & $36.5 \%$ & 0 & $3,574,097$ & 0.00 & 0 & 0.00 \\
\hline Georgia & 14 & $60.3 \%$ & $5,881,049$ & $3,806,604$ & 8.50 & 10 & 1.50 \\
\hline Hawaii & 2 & $21.3 \%$ & 0 & $1,360,211$ & 0.00 & 0 & 0.00 \\
\hline Idaho & 2 & $68.2 \%$ & $1,546,206$ & 21,376 & 1.97 & 2 & 0.03 \\
\hline Illinois & 18 & $46.0 \%$ & $6,327,569$ & $6,503,063$ & 8.88 & 7 & -1.88 \\
\hline Indiana & 9 & $57.8 \%$ & $4,403,689$ & $2,080,113$ & 6.11 & 7 & 0.89 \\
\hline lowa & 4 & $54.7 \%$ & $1,648,736$ & $1,397,619$ & 2.16 & 3 & 0.84 \\
\hline Kansas $^{38}$ & 4 & $68.6 \%$ & $2,575,254$ & 268,331 & 3.61 & 4 & 0.39 \\
\hline Kentucky & 6 & $70.7 \%$ & $3,598,271$ & 741,096 & 4.98 & 5 & 0.02 \\
\hline Louisiana & 6 & $67.1 \%$ & $3,579,010$ & 954,362 & 4.73 & 5 & 0.27 \\
\hline Maine & 2 & $48.0 \%$ & 685,652 & 642,709 & 1.03 & 1 & -0.03 \\
\hline Maryland & 8 & $37.0 \%$ & $2,078,729$ & $3,694,823$ & 2.88 & 1 & -1.88 \\
\hline Massachusetts & 9 & $16.1 \%$ & 0 & $6,547,629$ & 0.00 & 0 & 0.00 \\
\hline Michigan & 14 & $50.6 \%$ & $5,434,201$ & $4,449,439$ & 7.70 & 9 & 1.30 \\
\hline Minnesota & 8 & $48.2 \%$ & $2,063,674$ & $3,240,251$ & 3.11 & 3 & -0.11 \\
\hline Mississippi & 4 & $60.2 \%$ & $2,165,059$ & 802,238 & 2.92 & 3 & 0.08 \\
\hline Missouri & 8 & $60.6 \%$ & $3,996,521$ & $1,992,406$ & 5.34 & 6 & 0.66 \\
\hline Nebraska & 3 & $71.6 \%$ & $1,309,231$ & 517,110 & 2.15 & 3 & 0.85 \\
\hline Nevada & 4 & $49.5 \%$ & $1,007,011$ & $1,693,540$ & 1.49 & 1 & -0.49 \\
\hline N. Hampshire & 2 & $48.4 \%$ & 803,850 & 512,620 & 1.22 & 0 & -1.22 \\
\hline New Jersey & 12 & $45.8 \%$ & $3,417,346$ & $5,374,548$ & 4.66 & 5 & 0.34 \\
\hline New Mexico & 3 & $44.0 \%$ & 684,619 & $1,374,560$ & 1.00 & 1 & 0.00 \\
\hline
\end{tabular}




$\begin{array}{lrrrrrrr}\text { New York } & 27 & 36.2 \% & 5,535,110 & 13,842,992 & 7.71 & 9 & 1.29 \\ \text { North Carolina } & 13 & 53.3 \% & 5,121,073 & 4,414,410 & 6.98 & 10 & 3.02 \\ \text { Ohio } & 16 & 58.2 \% & 7,217,045 & 4,319,459 & 10.01 & 12 & 1.99 \\ \text { Oklahoma } & 5 & 71.9 \% & 3,751,351 & 0 & 5.00 & 5 & 0.00 \\ \text { Oregon } & 5 & 41.6 \% & 1,204,332 & 2,626,742 & 1.57 & 1 & -0.57 \\ \text { Pennsylvania } & 18 & 54.1 \% & 8,209,893 & 4,492,486 & 11.63 & 13 & 1.37 \\ \text { Rhode Island } & 2 & 34.9 \% & 0 & 1,052,567 & 0.00 & 0 & 0.00 \\ \text { South Carolina } & 7 & 59.8 \% & 3,739,998 & 885,366 & 5.66 & 6 & 0.34 \\ \text { Tennessee } & 9 & 64.7 \% & 4,772,993 & 1,573,112 & 6.76 & 7 & 0.23 \\ \text { Texas } & 36 & 60.7 \% & 16,437,819 & 8,707,742 & 23.53 & 25 & 1.47 \\ \text { Utah } & 4 & 66.6 \% & 1,697,906 & 1,065,979 & 2.46 & 4 & 1.54 \\ \text { Virginia } & 11 & 49.8 \% & 4,001,913 & 3,999,111 & 5.50 & 7 & 1.50 \\ \text { Washington } & 10 & 44.7 \% & 2,134,246 & 4,590,294 & 3.17 & 4 & 0.83 \\ \text { West Virginia } & 3 & 66.5 \% & 1,633,650 & 219,344 & 2.64 & 3 & 0.36 \\ \text { Wisconsin } & 8 & 47.9 \% & 3,191,830 & 2,495,156 & 4.49 & 5 & 0.51 \\ \text { TOTAL } & 401 & & 144,031,232 & 140,028,022 & 203.03 & 220 & 16.97\end{array}$

${ }^{38}$ An Independent won Cloud county (KS), earning a 0.01 seat benchmark for independents. 
TABLE A.6. ARTIFICIAL PARTISAN ADVANTAGE BY STATE, 2018 US HOUSE ELECTION

Pop. in counties won

State

Alabama

Arizona

Arkansas

California

Colorado

Connecticut

Georgia

Hawaii

Idaho

Illinois

Indiana

lowa

Kansas

Kentucky

Louisiana

Maryland

Massachusetts

Michigan

Minnesota

Mississippi ${ }^{39}$

Missouri

Nebraska

Nevada

N. Hampshire

New Jersey

New Mexico
[1] Seats [2] R vote

$7 \quad 59.0 \%$

$949.1 \%$

$4 \quad 64.0 \%$

$53 \quad 33.1 \%$

$7 \quad 44.6 \%$

$5 \quad 38.0 \%$

$14 \quad 52.3 \%$

$2 \quad 23.3 \%$

$2 \quad 63.9 \%$

$18 \quad 38.9 \%$

$955.5 \%$

$4 \quad 47.9 \%$

$4 \quad 54.8 \%$

$6 \quad 60.4 \%$

$6 \quad 59.1 \%$

$833.1 \%$

$9 \quad 20.4 \%$

$14 \quad 46.0 \%$

$8 \quad 44.2 \%$

$4 \quad 54.2 \%$

$856.4 \%$

$3 \quad 62.0 \%$

$4 \quad 47.2 \%$

$244.4 \%$

$12 \quad 39.2 \%$

$3 \quad 39.6 \%$

\section{[3] by $R \quad$ [4] by $D$}

$3,402,297 \quad 1,377,439$

$3,249,919 \quad 3,142,098$

$2,332,594$

583,324

$5,814,617 \quad 31,429,339$

$1,981,523 \quad 3,047,673$

$189,927 \quad 3,384,170$

$4,510,631 \quad 5,177,022$

$0 \quad 1,360,211$

$1,498,792$

68,790

$2,798,967 \quad 10,031,665$

$4,286,018 \quad 2,197,784$

$1,307,082 \quad 1,739,273$

$1,791,559 \quad 1,061,559$

$3,253,183 \quad 1,086,184$

$3,567,807$

965,565

$1,249,709 \quad 4,523,843$

$0 \quad 6,547,629$

$4,041,237 \quad 5,842,403$

1,975,159 3,328,766

$2,070,236$

886,464

$3,833,879 \quad 2,155,048$

$1,023,824$

802,517

$749,282 \quad 1,951,269$

$60,088 \quad 1,256,382$

$1,659,336 \quad 7,132,558$

$515,164 \quad 1,544,015$
Republican Seats

[5] Earned [6] Total [7] Art. Adv.

$\begin{array}{lll}4.98 & 6 & 1.02\end{array}$

$\begin{array}{lll}4.58 & 4 & -0.58\end{array}$

3.20

$\begin{array}{lll}8.27 & 7 & -1.27\end{array}$

2.76

0.27

6.52

0.00

1.91

3.93

5.95

1.72

2.51

4.50

4.72

1.73

0.00

5.72

2.98

2.79

5.12

1.68

1.11

0.09

2.26

0.75 $\begin{array}{ll}4 & 0.80\end{array}$

$3 \quad 0.24$

$\begin{array}{ll}0 & -0.27\end{array}$

$9 \quad 2.48$

$\begin{array}{ll}0 & 0.00\end{array}$

20.09

$\begin{array}{ll}5 & 1.07\end{array}$

$7 \quad 1.05$

$\begin{array}{ll}1 & -0.72\end{array}$

$3 \quad 0.49$

$5 \quad 0.50$

$5 \quad 0.28$

$1-0.73$

$0 \quad 0.00$

$\begin{array}{ll}7 & 1.28\end{array}$

$3 \quad 0.02$

$3 \quad 0.21$

$\begin{array}{ll}6 & 0.88\end{array}$

31.32

$1-0.11$

$0 \quad-0.09$

$1-1.26$

$0 \quad-0.75$ 


$\begin{array}{lrrrrrrr}\text { New York } & 27 & 31.8 \% & 2,566,306 & 16,811,796 & 3.58 & 6 & 2.42 \\ \text { North Carolina } & 13 & 51.0 \% & 4,871,767 & 4,663,716 & 6.64 & 10 & 3.36 \\ \text { Ohio } & 16 & 52.4 \% & 6,253,252 & 5,283,252 & 8.67 & 12 & 3.33 \\ \text { Oklahoma } & 5 & 63.0 \% & 3,032,718 & 718,633 & 4.04 & 4 & -0.04 \\ \text { Oregon } & 5 & 39.8 \% & 925,060 & 2,906,014 & 1.21 & 1 & -0.21 \\ \text { Pennsylvania } & 18 & 44.9 \% & 5,949,677 & 6,752,702 & 8.43 & 9 & 0.57 \\ \text { Rhode Island } & 2 & 34.9 \% & 0 & 1,052,567 & 0.00 & 0 & 0 \\ \text { South Carolina } & 7 & 55.0 \% & 3,428,681 & 1,196,683 & 5.19 & 5 & -0.19 \\ \text { Tennessee } & 9 & 60.2 \% & 4,772,993 & 1,573,112 & 6.77 & 7 & 0.23 \\ \text { Texas } & 36 & 51.8 \% & 13,152,355 & 11,993,206 & 18.83 & 23 & 4.17 \\ \text { Utah } & 4 & 62.3 \% & 1,688,681 & 1,075,204 & 2.44 & 3 & 0.56 \\ \text { Virginia } & 11 & 43.0 \% & 2,793,698 & 5,207,326 & 3.84 & 4 & 0.16 \\ \text { Washington } & 10 & 36.7 \% & 1,664,107 & 5,060,433 & 2.47 & 3 & 0.53 \\ \text { West Virginia } & 3 & 59.0 \% & 1,493,074 & 359,920 & 2.42 & 3 & 0.58 \\ \text { Wisconsin } & 8 & 46.1 \% & 2,882,782 & 2,804,204 & 4.06 & 5 & 0.94 \\ \text { TOTAL } & 399 & & 112,637,981 & 170,091,848 & 158.65 & 181 & 22.35\end{array}$

${ }^{39}$ An Independent won Carroll county (MS), earning 0.01 seats for independents. 
TABLE A.8. CORRELATION OF RESULTS ACROSS ELECTIONS

\begin{tabular}{|c|c|c|c|c|c|c|}
\hline & \multicolumn{2}{|c|}{2014} & \multicolumn{2}{|c|}{2016} & \multicolumn{2}{|c|}{2018} \\
\hline \multirow{2}{*}{2012} & 0.552 & 0.445 & 0.781 & 0.725 & 0.520 & 0.495 \\
\hline & 0.348 & 0.531 & 0.679 & 0.710 & 0.411 & 0.507 \\
\hline \multirow{2}{*}{2014} & & & 0.549 & 0.643 & 0.343 & 0.354 \\
\hline & & & 0.611 & 0.620 & 0.153 & 0.288 \\
\hline \multirow{2}{*}{2016} & & & & & 0.656 & 0.694 \\
\hline & & & & & 0.415 & 0.641 \\
\hline
\end{tabular}

For each pair of elections, the top-left cell indicates the Pearson correlation coefficient of the Artificial Partisan Advantage across states; the top-right indicates the Spearman rank-order correlation coefficient of the Artificial Partisan Advantage; the bottom-left indicates the Pearson correlation coefficient of the Excess Artificial Partisan Advantage; and the bottom-right indicates the Spearman rank-order correlation coefficient of the Excess Artificial Partisan Advantage (positive values indicate a positive correlation; negative values a negative correlation; possible values range from -1 to 1$)$. 
TABLE A.9. ARTIFICIAL PARTISAN ADVANTAGE BY STATE, 2012-2018

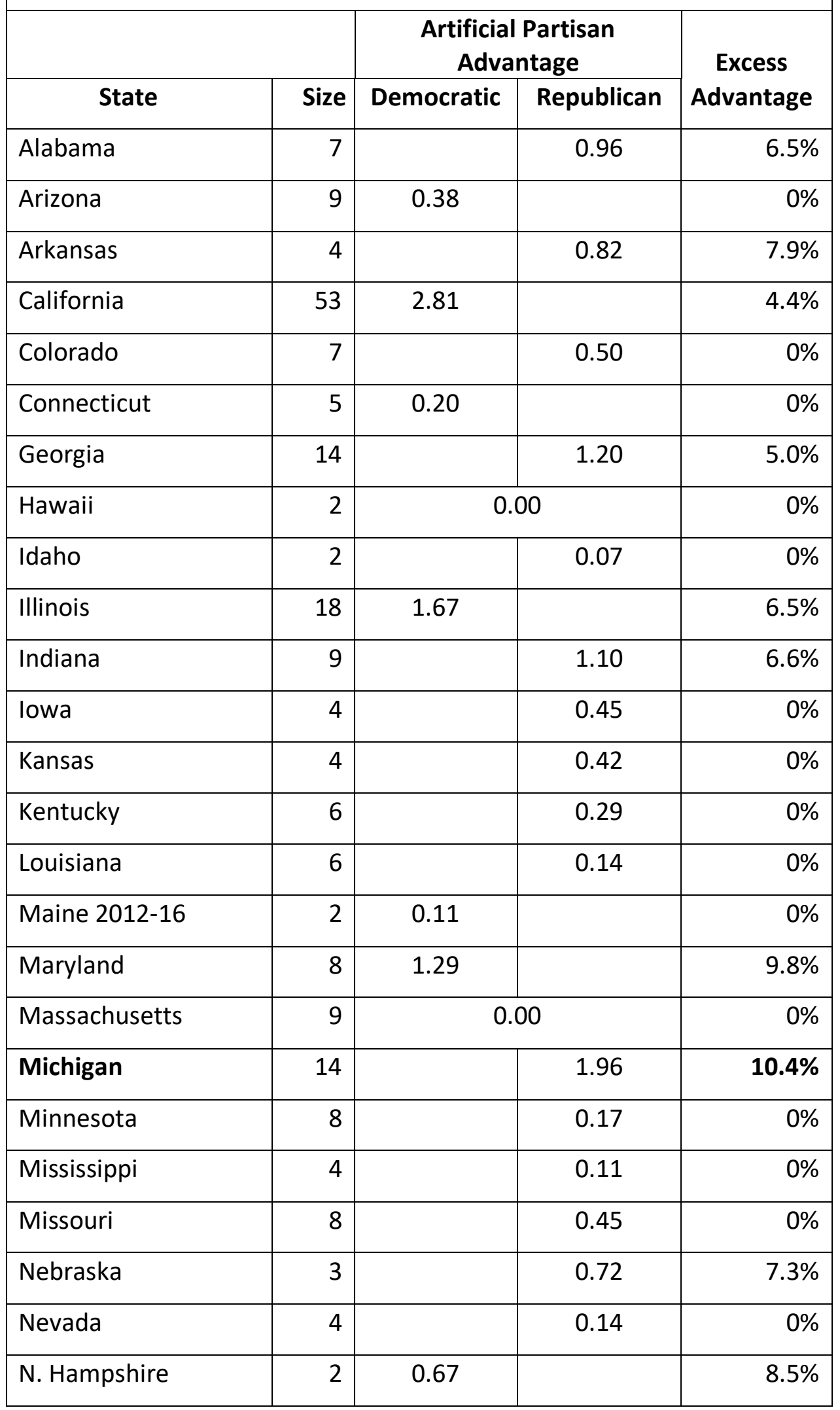




\begin{tabular}{|c|c|c|c|c|}
\hline New Jersey & 12 & & 0.62 & $1.0 \%$ \\
\hline New Mexico & 3 & 0.26 & & $0 \%$ \\
\hline New York & 27 & & 1.17 & $2.5 \%$ \\
\hline North Carolina 12-14 & 13 & & 2.54 & $15.8 \%$ \\
\hline $16-18$ & 13 & & 3.19 & $20.7 \%$ \\
\hline Ohio & 16 & & 2.15 & $10.3 \%$ \\
\hline Oklahoma & 5 & 0.01 & & $0 \%$ \\
\hline Oregon & 5 & 0.41 & & $0 \%$ \\
\hline Pennsylvania '12-'16 & & & 1.85 & $7.5 \%$ \\
\hline 2018 & 18 & & 0.57 & $0.4 \%$ \\
\hline Rhode Island & 2 & 0.02 & & $0 \%$ \\
\hline South Carolina & 7 & & 0.45 & $0 \%$ \\
\hline Tennessee & 9 & & 0.26 & $0 \%$ \\
\hline Texas & 36 & & 2.28 & $4.9 \%$ \\
\hline Utah & 4 & & 1.05 & $13.6 \%$ \\
\hline Virginia '12 & 11 & & 1.57 & $9.7 \%$ \\
\hline '14-'18 & 11 & & 0.83 & $3.0 \%$ \\
\hline Washington & 10 & & 0.73 & $2.3 \%$ \\
\hline West Virginia & 3 & & 0.51 & $0.2 \%$ \\
\hline Wisconsin & 8 & & 0.64 & $1.8 \%$ \\
\hline TOTAL & 401 & & 17.26 & \\
\hline
\end{tabular}

The artificial partisan advantage is the average from 2012 to 2018, except as noted in the table. The "excess advantage" column is computed as the artificial partisan advantage minus 0.5 , divided by the size of the delegation. Values above $10 \%$ are in bold. The excess advantage for states with a value of artificial partisan advantage below 0.5 is $0 \%$. 


\begin{tabular}{|c|c|c|c|c|}
\hline \multicolumn{5}{|c|}{$\begin{array}{l}\text { TABLE A.10. ARTIFICIAL PARTISAN ADVANTAGE BY STATE, USING } 20 \\
\text { PRESIDENTIAL ELECTION RESULTS }\end{array}$} \\
\hline \multirow[b]{2}{*}{ State } & \multirow[b]{2}{*}{ Size } & \multicolumn{2}{|c|}{ Artificial Partisan GOP Advantage } & \multirow{2}{*}{$\begin{array}{l}\text { Excess Avg. } \\
\text { Advantage }\end{array}$} \\
\hline & & 2012 & 2016 & \\
\hline Alabama & 7 & 0.69 & 0.63 & $2.2 \%$ \\
\hline Arizona & 9 & 0.77 & -0.23 & $0 \%$ \\
\hline Arkansas & 4 & 0.53 & 0.82 & $8.1 \%$ \\
\hline California & 53 & -1.72 & -0.08 & $-0.8 \%$ \\
\hline Colorado & 7 & 0.53 & 0.24 & $0 \%$ \\
\hline Connecticut & 5 & 0.00 & -0.43 & $0 \%$ \\
\hline Florida 2012 & 27 & 3.06 & $\mathrm{x}$ & $9.5 \%$ \\
\hline Florida 2016 & 27 & $\mathrm{X}$ & -0.72 & $0.8 \%$ \\
\hline Georgia & 14 & 1.14 & 3.49 & $13.0 \%$ \\
\hline Hawaii & 2 & 0.00 & 0.00 & $0 \%$ \\
\hline Idaho & 2 & 0.07 & 0.07 & $0 \%$ \\
\hline Indiana & 9 & 1.23 & 0.50 & $4.0 \%$ \\
\hline lowa & 4 & -0.29 & 1.52 & $3.0 \%$ \\
\hline Kansas & 4 & 0.38 & -0.62 & $0 \%$ \\
\hline Kentucky & 6 & 0.51 & 0.43 & $0 \%$ \\
\hline Louisiana & 6 & 0.56 & 0.56 & $1.0 \%$ \\
\hline Maine & 2 & -0.03 & 0.03 & $0 \%$ \\
\hline Maryland & 8 & -1.84 & -1.14 & $-12.4 \%$ \\
\hline Massachusetts & 9 & 0.00 & 0.00 & $0 \%$ \\
\hline Michigan & 14 & 4.04 & 1.46 & $16.1 \%$ \\
\hline Minnesota & 8 & -1.13 & 1.06 & $0 \%$ \\
\hline Mississippi & 4 & 0.23 & 0.08 & $0 \%$ \\
\hline Missouri & 8 & 0.88 & 0.88 & $4.7 \%$ \\
\hline Nebraska & 3 & 0.01 & 1.32 & $5.5 \%$ \\
\hline Nevada & 4 & 0.13 & 1.13 & $3.3 \%$ \\
\hline
\end{tabular}




\begin{tabular}{|c|c|c|c|c|}
\hline New Hampshire & 2 & -0.61 & -0.34 & $0 \%$ \\
\hline New Jersey & 12 & 1.02 & 1.54 & $6.5 \%$ \\
\hline New Mexico & 3 & 0.21 & 0.07 & $0 \%$ \\
\hline New York & 27 & 0.50 & 0.98 & $0.9 \%$ \\
\hline North Carolina 2012 & 13 & 3.48 & & $22.9 \%$ \\
\hline 2016 & 13 & & 2.99 & $19.1 \%$ \\
\hline Ohio & 16 & 5.05 & 2.70 & $21.1 \%$ \\
\hline Oklahoma & 5 & 0.00 & 0.00 & $0 \%$ \\
\hline Oregon & 5 & -1.05 & -1.15 & $-12.0 \%$ \\
\hline Pennsylvania & 18 & 4.62 & 3.05 & $18.5 \%$ \\
\hline Rhode Island & 2 & 0.00 & -0.32 & $0 \%$ \\
\hline South Carolina & 7 & 1.12 & 0.84 & $6.8 \%$ \\
\hline Tennessee & 9 & 0.27 & 0.23 & $0 \%$ \\
\hline Texas & 36 & 4.03 & 1.55 & $6.4 \%$ \\
\hline Virginia 2012 & 11 & 1.83 & $\mathrm{X}$ & $12.1 \%$ \\
\hline Virginia 2016 & 11 & $x$ & 0.77 & $2.4 \%$ \\
\hline Washington & 10 & 0.64 & 0.22 & $0 \%$ \\
\hline West Virginia & 3 & 0.00 & 0.00 & $0 \%$ \\
\hline Wisconsin & 8 & 1.32 & 0.84 & $7.3 \%$ \\
\hline TOTAL & 401 & 32.95 & 25.71 & \\
\hline
\end{tabular}

\section{REFERENCES}

-Bernstein, Mira, and Moon Duchin. "A formula goes to court: Partisan gerrymandering and the efficiency gap." Notices of the American Mathematical Society 64.9: 1020-1024 (2017). 
-Butler, David E. "Appendix: An examination of the results." The British General Election of 1950, Ed. H.G. Nicholas, 306-333. McMillan, London, 1951.

-Butler, David E. The British General Election of 1951. McMillan, London 1952.

-Chambers, Christopher P., and Alan D. Miller. "A measure of bizarreness." Quarterly Journal of Political Science 5.1: 27-44 (2010).

-Chambers, Christopher P., Alan D. Miller, and Joel Sobel. "Flaws in the efficiency gap." Journal of Law and Politics. 33: 1-33 (2017).

-Chen, Jowei and David Cottrell. "Evaluating partisan gains from congressional gerrymandering: using computer simulations to estimate the effect of gerrymandering in the U.S. House." Electoral Studies 44: 329-340 (2016).

-Chen, Jowei, and Jonathan Rodden. "Unintentional gerrymandering: Political geography and electoral bias in legislatures." Quarterly Journal of Political Science 8.3: 239-269 (2013).

-Chen, Jowei and Jonathan Rodden. "Cutting through the Thicket: Redistricting Simulations and the Detection of Partisan Gerrymanders." Election Law Journal 14(4): 331-345 (2015).

-Cho, Wendy K. Tam. "Technology-enabled coin flips for judging partisan gerrymandering." Southern California Law Review Postscript 93: 11-27 (2019).

-Cho, Wendy K. Tam, and Yan Y. Liu. "Toward a talismanic redistricting tool: a computational method for identifying extreme redistricting plans." Election Law Journal 15(4): 351-366 (2016). 
-Cox, Gary W., and Jonathan N. Katz. "The reapportionment revolution and bias in US congressional elections." American Journal of Political Science 43.3: 812-841 (1999).

-Curiel, John A., and Tyler Steelman. "Redistricting out representation. Democratic harm in splitting zip-codes." Election Law Journal 17.4: 328-353 (2018).

-Duchin, Moon. “Geometry v. Gerrymandering." Scientific American 319.5: 48-53 (2018).

-Edgeworth, Frances Y. "Miscellaneous applications of the calculus of probabilities." Journal of the Royal Statistical Society 61.3: 534-544 (1898).

-Erikson, Robert S. "Malapportionment, Gerrymandering, and Party Fortunes in Congressional Elections." American Political Science Review 66: 1234-45 (1972).

-Goedert, Nicholas. "The case of the disappearing bias: a 2014 update to the 'Gerrymandering or geography' debate." Research \& Politics 2.4: 1-6 (2015).

-Grofman, Bernard. "Measures of bias and proportionality in seats-votes relationships." Political Methodology 9.3: 295-327 (1983).

-Grofman, Bernard, and Gary King. "The future of partisan symmetry as a judicial test for partisan gerrymandering after LULAC v. Perry." Election Law Journal 6.1: 2-35 (2007).

-Katz, Jonathan, Gary King, and Elizabeth Rosenblatt. "Theoretical foundations and empirical evaluations of partisan fairness in district-based democracies." American Political Science Review 114.1: 164-178 (2020).

-King, Gary, and Robert X. Browning. "Democratic representation and partisan bias in Congressional elections." American Political Science Review 81.4: 1251-1273 (1987). 
-Kromkowski, Charles A. Recreating the American Republic. Cambridge U. Press. Cambridge, U.K.

-McDonald, Michael D., and Robin E. Best. "Unfair partisan gerrymanders in politics and law: A diagnostic applied to six cases." Election Law Journal 14.4: 312-330 (2015).

-McGhee, Eric. "Measuring partisan bias in single-member district electoral systems." Legislative Studies Quarterly 39.1: 55-85 (2014).

-Pole, Jack R.. Political representation in England and the origins of the American Republic. New York: St. Martin's P. (1966).

-Rodden, Jonathan. Why cities lose: The deep roots of the urban-rural political divide. Basic Books, 2019.

-Royden, Laura, and Michael Li. "Extreme maps." Brennan Center for Justice at New York University School of Law (2017).

-Rush, Mark. "The Efficiency Gap after Gill v. Whitford." Social Science Quarterly 101.1: 53-67 (2020).

-Saxon, James. "Spatial constraints on gerrymandering. A practical comparison of methods." Working paper (2019). https://saxon.harris.uchicago.edu/ jjsaxon/c4_pa_181112.pdf

-Squire, Peveril. "The beginnings of representation in America: the relationship between representatives and constituents in the Colonial Era." Conference paper, "Political Representation: Fifty Years After Miller \& Stokes", Vanderbilt, 2013.

-Stephanopoulos, Nicholas O., and Eric M. McGhee. "Partisan gerrymandering and the efficiency gap." Chicago Law Review 82: 831-900 (2015). 
-Stephanopoulos, Nicholas O., and Eric M. McGhee. "The measure of a metric: The debate over quantifying partisan gerrymandering." Stanford Law Review 70: 1503-1568 (2018).

-Tufte, Edward R. "The relationship between seats and votes in two-party systems." American Political Science Review 67: 540-554 (1973).

-Wang, Samuel S.-H. "Three tests for practical evaluation of partisan gerrymandering." Stanford Law Review. 68: 1263-1322 (2016).

-Warrington, Gregory S. "Quantifying gerrymandering using the vote distribution." Election Law Journal 17.1: 39-57 (2018). 


\section{ONLINE APPENDIX}

This file is the online appendix to the article "Artificial partisan advantage in redistricting," by

Jon X. Eguia. This version is dated September 12, 2020. This online appendix contains the following supporting information:

OA1. State-by-state analysis, for the states of greatest interest.

OA2. A discussion of caveats, limitations and remedies of the artificial partisan advantage measure. 


\section{SECTION OA.1. RESULTS BY STATE}

States differ in their redistricting procedures. In most of them, the legislature draws the maps, with or without veto power for the governor. In some states, a commission, either appointed by legislators or drawn from a pool of volunteer citizens, controls the process. While the number of states in each category of process is too small to draw rigorous statistical inferences about the effect of control of the redistributing process over the resulting partisanship of the maps, some comparisons are instructive.

The five maps with the greatest excess artificial advantage were drawn by legislatures controlled by one party: the GOP in North Carolina, Utah, Michigan and Ohio, and the Democratic Party in Maryland. In all four cases the excess advantage is at least close to $10 \%$, and in all four cases it favors the party that drew the maps.

Maps drawn by legislatures under split partisan control in Colorado, lowa, Kentucky, Mississippi and New Mexico drew neutral maps, with no excess advantage. Maps drawn by appointed bipartisan commissions in Hawaii, Idaho, New Jersey and Washington drew maps that are either neutral, or exhibit a very small excess partisan advantage for the GOP. Maps drawn by judicial courts in New York, Pennsylvania and Virginia also show a very small (from $0 \%$ to $3 \%$ ) excess artificial advantage for the GOP. The independent citizens' commissions in Arizona drew a neutral map, and the one in California drew maps with a $4 \%$ excess artificial advantage for the Democratic Party. Figure OA.1 illustrates the findings. 


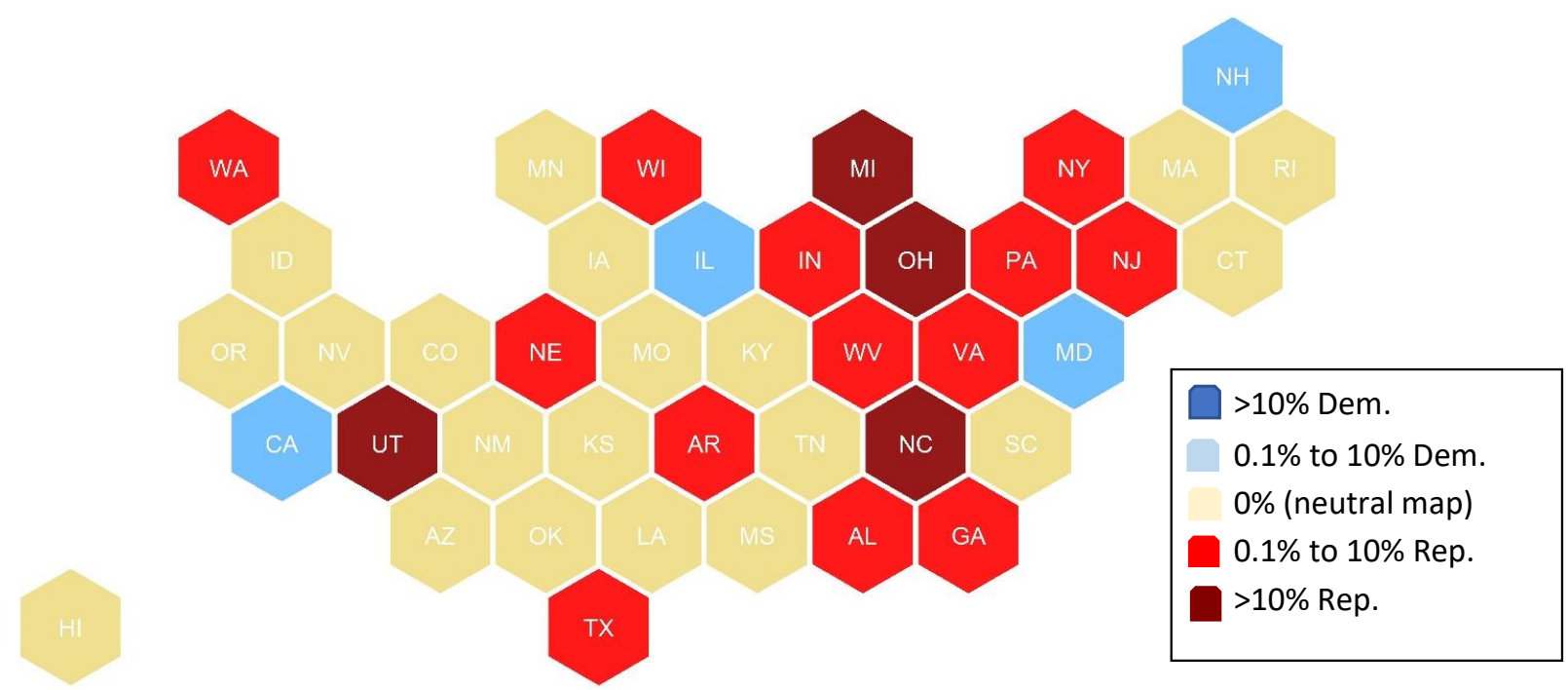

Figure OA. 1 Excess Artificial Partisan Advantage

In the remainder of this section I describe the redistricting process and the results in the four states with an excess artificial advantage greater than $10 \%$ of the state's delegation (North Carolina, Utah, Michigan and Ohio), or the one closest to this cut-off (Maryland), as indicated in Table 1 in the main paper. For comparison, I also discuss the six states in which the maps were drawn by independent citizens' commissions (Arizona and California), or by the Courts (New York, Pennsylvania, Texas and Virginia).

Note that all four states' congressional maps that were declared unconstitutional partisan gerrymanders by federal courts -the maps of North Carolina, Maryland, Michigan and Ohio- are among the top five worst offenders according to the excess artificial advantage measure. ${ }^{40}$

\footnotetext{
${ }^{40}$ As referenced above, these rulings were later vacated by the Supreme Court ruling in Rucho v. Common Cause (2019), where it held that partisan gerrymandering claims are not justiciable in federal courts.
} 


\section{North Carolina}

In North Carolina, district maps are drawn by the legislature, which throughout 2011-18 has been under Republican control. The state's delegation has 13 seats. The congressional maps were struck down in 2016 as a racial gerrymander, forcing the legislature to draw remedial maps for the 2016 and 2018 elections. ${ }^{41}$

North Carolina is on a class of its own, because it is the only state in which the map-drawers have explicitly acknowledged that the deliberately designed the redistricting maps to be a partisan gerrymander. Mark Lewis, chair of the NC General Assembly's redistricting committee, argued that the redrawn maps are not a racial gerrymander, because their design is partisan, not racial; their intent is to elect as many Republicans as possible. In Lewis's words: "I think electing Republicans is better than electing Democrats. [...] So I drew this map to help foster what I think is better for the country." And: "I propose that we draw the maps to give a partisan advantage to 10 Republicans and three Democrats because I do not believe it's possible to draw a map with 11 Republicans and two Democrats." 42

These redrawn maps were challenged in Court, and ruled unconstitutional in a series of Common Cause v Rucho cases (consolidated with League of Women Voters v Rucho): a panel District Court found these remedial maps unconstitutional in January 2018; in July 2018 SCOTUS vacated the January 2018 district court ruling and sent the case back to the district court for reconsideration; and in August 2018 the district panel reaffirmed its previous decision, once again

${ }^{41}$ Harris v McCrory, 159 F. Supp. 3d 600, (M.D.N.C. 2016); later affirmed in Cooper v. Harris, No. 15-1262, 581 U.S. (2017).

${ }^{42}$ Common Cause v Rucho, 318 F. Supp. 3d 777, 808-809 (M.D.N.C 2018) 
declaring the remedial maps unconstitutional and requiring a second set of remedial maps. ${ }^{43}$ SCOTUS decided in September 2018 to let the 2018 election be held under the challenged maps, and in June 2019, it vacated the lower court ruling, declaring partisan gerrymandering "not justiciable" under federal courts. ${ }^{44}$ In October 2019 a state Superior Court blocked the use of these maps. In November 2019, the assembly drew new remedial maps for use in the 2020 election. ${ }^{45}$ These new maps are expected to reduce the artificial partisan advantage to one seat.

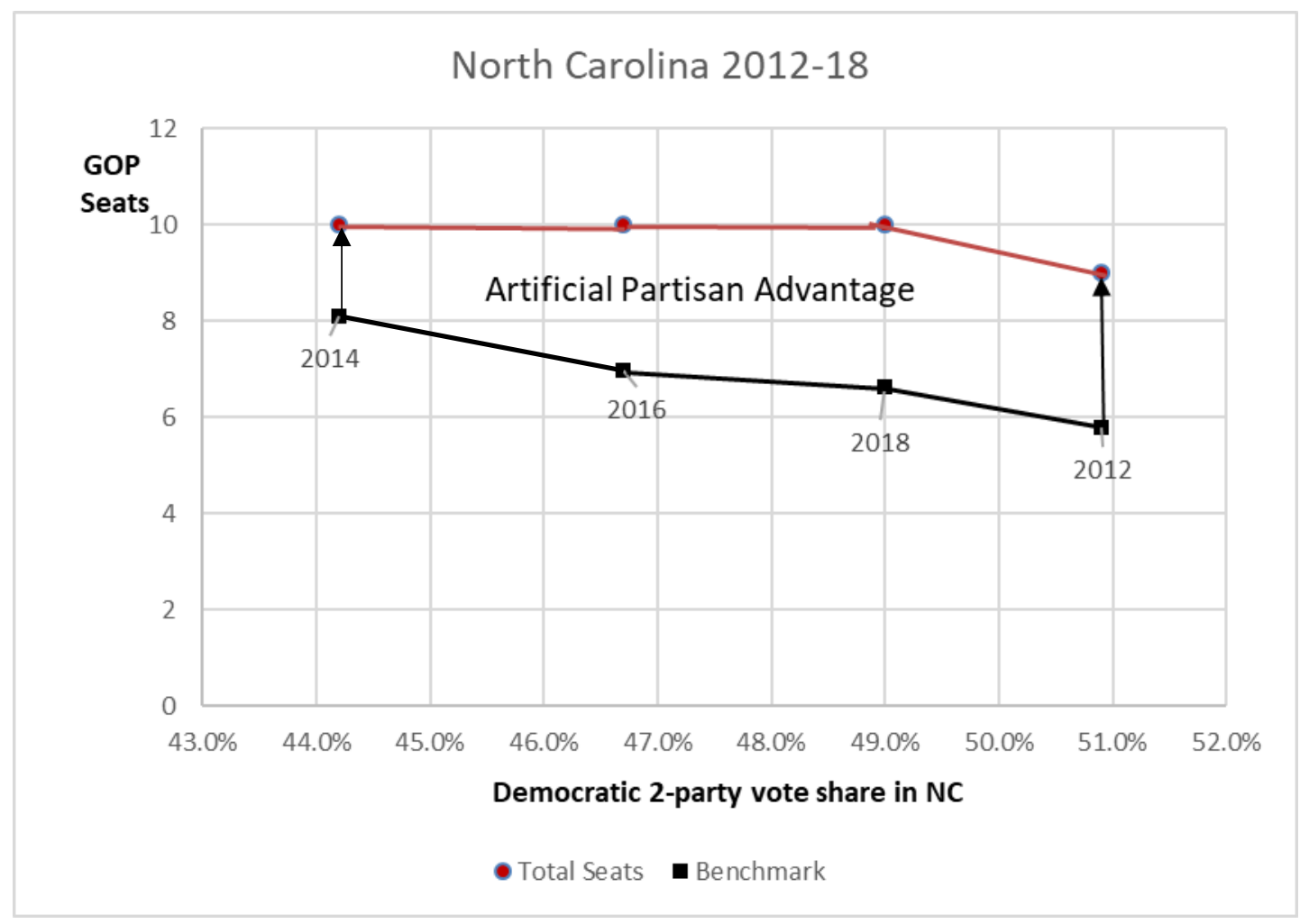

Figure OA. 2 Artificial Partisan advantage in North Carolina, 2012-2018.

${ }^{43}$ The three rulings are, respectively, Common Cause v. Rucho, 279 F. Supp. 3d 587 (M.D.N.C. 2018); Rucho v. Common Cause, 138 S. Ct. 2679 (2018) and Common Cause v. Rucho, 318 F. Supp. 3d 777 (M.D.N.C. 2018).

${ }^{44}$ Rucho v. Common Cause, No. 18-422, 588 U.S. (2019).

${ }^{45}$ Harper v. Lewis, 19 CVS 012667 Wake County Superior Court, North Carolina (2019). 
Because the North Carolina maps are known to be a partisan gerrymander, they provide a test of minimum efficacy for a measure: any new measure of partisan gerrymandering ought to identify North Carolina's 2016 remedial maps as a partisan gerrymandering. The artificial partisan advantage measure passes this test.

North Carolina exhibits the greatest artificial partisan advantage of any state. The 2016 remedial maps were drawn to attain a 10-3 Republican majority delegation, and they attain this outcome for all likely election results. In 2016 and 2018, the Republican party obtained 53\% of the two-party vote, and it won in counties with $5,121,000$ citizens, or $53.7 \%$ of the total population, earning close to 7 of the 13 seats according to the county-based seat benchmark. But it won 10 seats, as designed by the plans.

In 2018 , its vote share decreased to $51.0 \%$, and the population in counties it won decreased to $51.1 \%$ of the state, earning 6.5 seats. And yet, the Republican party won 10 seats. ${ }^{46}$ The artificial partisan advantage for the GOP averaged over the two elections is 3.2 seats. The excess artificial partisan advantage is over $18 \%$.

\section{Utah}

The size of Utah's delegation is four seats. The legislature draws the congressional districts' map, and its map has not been challenged in Court.

The Democrats have won Salt Lake county in every election in this cycle. Salk Lake is the largest of the state, home to just over a million citizens, and hence worth one and a half congressional districts. Nevertheless, in 2014 and 2016 the state delegation was a GOP 4-0

\footnotetext{
${ }^{46}$ The GOP won NC-9 district on a re-run.
} 
majority (in 2012 and 2018 the Democratic party obtained one seat). The GOP's artificial partisan advantage of over one and a half seats in 2014 and 2016, and over half a seat in 2012 and 2018 averages to 1.05 seats over these elections; the excess artificial advantage is $13.7 \%$.

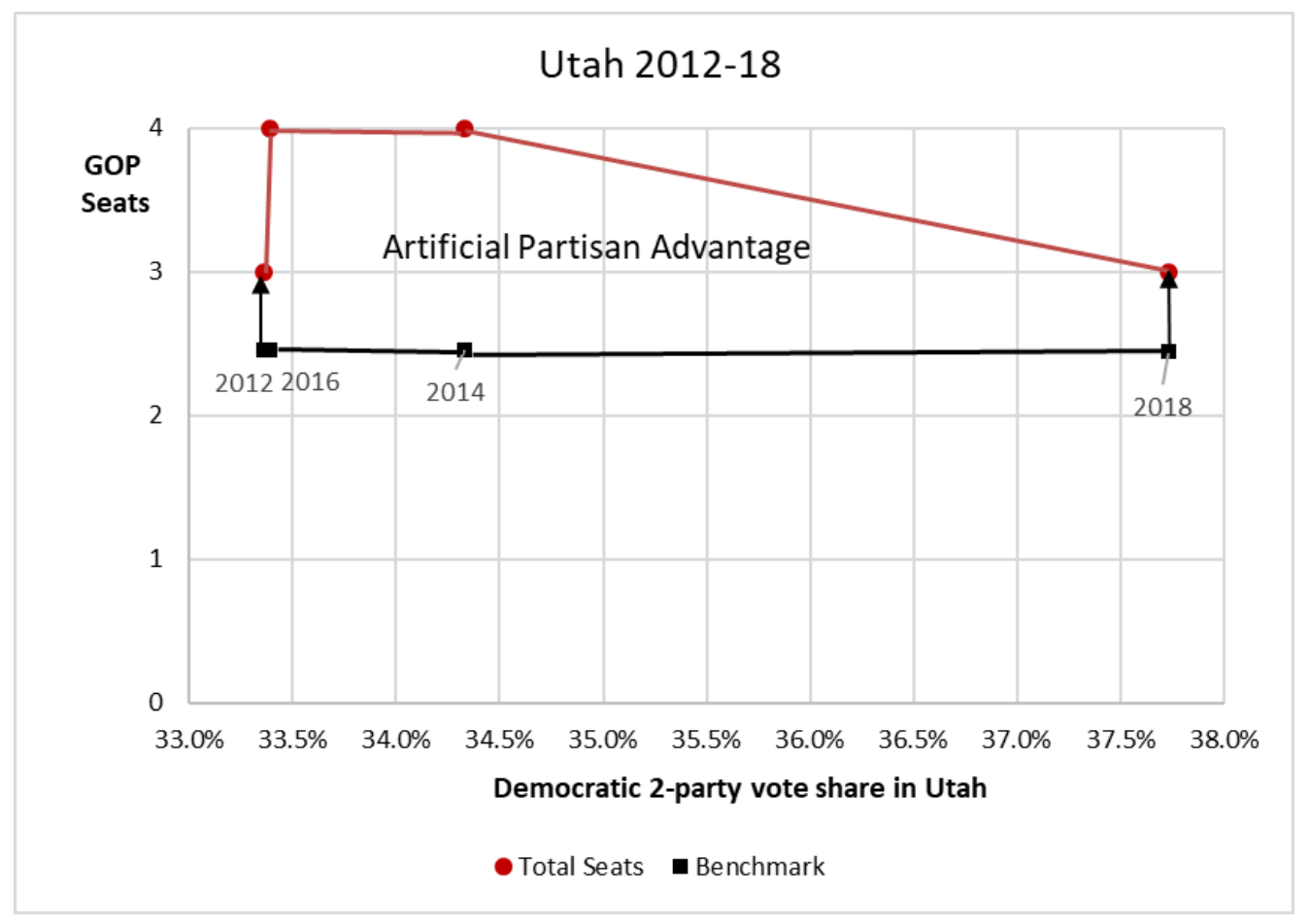

Figure OA. 3 Artificial Partisan advantage in Utah, 2012-2018.

Utah voters have approved a ballot initiative to create a commission with some powers to influence the redistricting process after the 2020 census. With current voting patterns, the state delegation should alternative between 1 or 2 Democrats, as opposed to alternating between 0 or 1 as it has occurred during the 2012-20 redistricting cycle. 


\section{Michigan}

In Michigan, the state legislature drew the districts for the 2012-2020 election cycle, but after an amendment to the Michigan Constitution passed in a ballot initiative in 2018, an independent citizens' commission will draw the maps for the 2022-2030 cycle. The state had a delegation of 14 seats. From 2011 to 2019, the Michigan legislature has been controlled by the Republican Party.

The maps drawn in 2011 by the legislature were ruled to be an unconstitutional partisan gerrymander in League of Women Voters v. Benson (2019), but this ruling was later voided by SCOTUS's ruling in Rucho v. Common Cause (2019).

In 2012, the Republican Party obtained $47.3 \%$ of the two-party vote in Michigan, and only won in counties with $39.4 \%$ of the population, corresponding to 5.52 seats according to the county-based benchmark. However, the party obtained a 9-5 seat majority, which it kept in 2014 and 2016 , despite obtaining only approximately $50 \%$ of the two-party vote and winning in counties with little over $50 \%$ of the population in each election. In 2018 , the Republican party share of the two-party vote decreased to $46 \%$, and the share of population in counties it won decreased to $40.9 \%$, corresponding to 5.72 seats according to the benchmark, but the party won 7 seats. Thus, the artificial partisan advantage averaged to almost two seats over the four elections, with an excess artificial advantage above $10 \%$. 


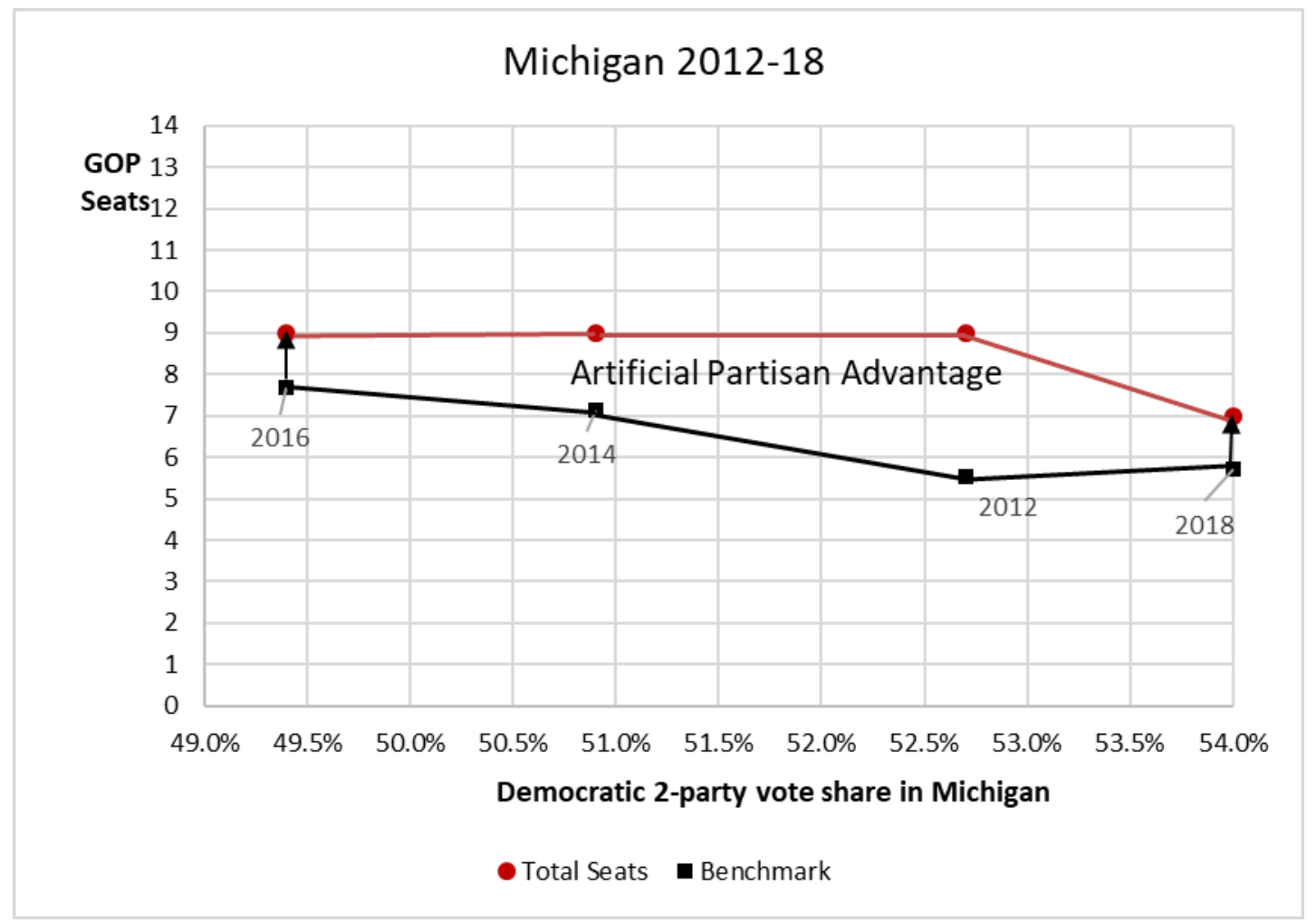

Figure OA. 4 Artificial Partisan advantage in Michigan, 2012-2018.

In anticipation of the formation of a new Independent Citizens' Redistricting Commission for the 2022-2030 redistricting cycle, and to provide information to this commission, uniquely for the State of Michigan I also computed the artificial partisan advantage in the Michigan Senate and the Michigan House of Representatives, and I extended the analysis back to the previous redistricting cycle, so I provide results for all three chambers from 2002 to 2018.

I find that the 2012-2020 maps provide an artificial partisan advantage to the GOP in all three chambers, but the excess advantage is greatest for the US House (over 10\%) and smaller for the Michigan Senate (7\%) and the Michigan House (2\%). The 2002-2010 maps provided smaller advantages to the GOP, with an excess advantage of only $2 \%$ for the US House and $6 \%$ for the Michigan Senate, and neutral maps for the Michigan House. Detailed results, and original data for each year, are available from the author. 


\section{Ohio}

In Ohio, the state legislature draws the district maps. The state delegation has 16 seats. The legislature has been under GOP control since 2011. In May 2018, voters approved a ballot initiative to reform the redistricting process. In response, the legislature changed its redistricting rules, to encourage a more bipartisan drawing of maps, and to make it more difficult -but not impossible- for a majority to draw a partisan gerrymander. In 2019, a federal District Court ruled the 2011 maps to be an unconstitutional partisan gerrymander in Phillips Randolph Institute $v$ Householder (2019); as noted above, this ruling was voided by SCOTUS's subsequent ruling that partisan gerrymandering claims are not justiciable by federal courts in Rucho v. Common Cause (2019).

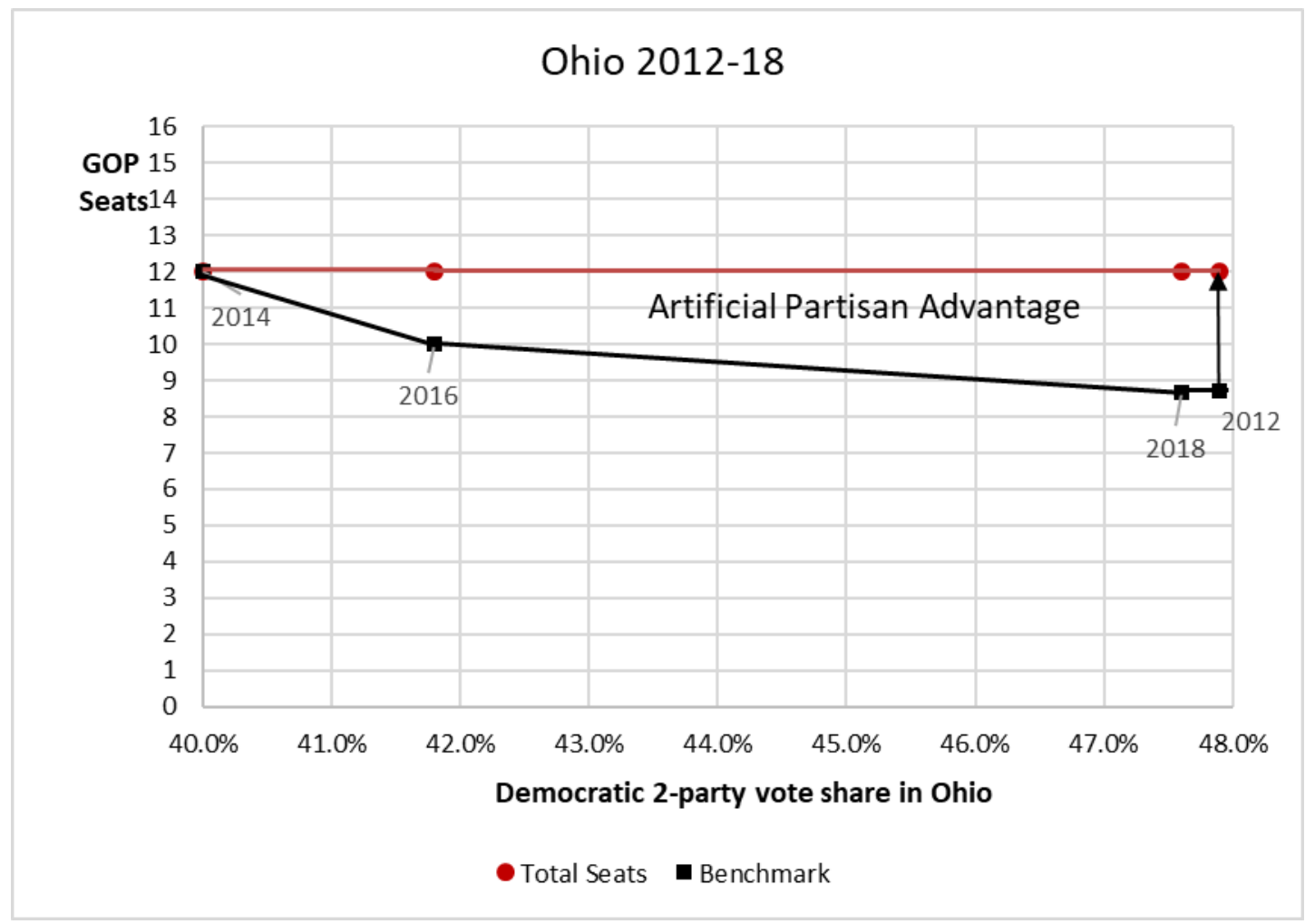

Figure OA. 5 . Artificial Partisan advantage in Ohio, 2012-2018. 
It is instructive to look first at the results in the 2014 election, a Republican landslide. In Ohio, the Republican party won over $60 \%$ of the two-party vote, and counties with over $75 \%$ of the population of Ohio, corresponding to almost exactly 12 seats according to the county-based benchmark. The party won precisely a 12-4 seat majority so on the evidence of 2014 alone, the redistricting map would seem neutral.

When we consider other election years, we find that as the electoral environment worsens for the Republican party, its seat outcome does not. In 2016 the party's share of the two-party vote dropped to $58 \%$, and in 2018 to $52 \%$ (the same as in 2012 ); the share of population in counties won by the party dropped to $62 \%$ in 2016 and to 54\% in 2018 (as in 2012), and hence the seat benchmark dropped to 10 in 2016 and 8.7 in 2018 (and in 2012)... and yet, the Republican party kept the same 12-4 seat majority across all these elections. With the 2011 redistricting maps, for any voting tally within the range of plausible scenarios, the seat outcome is the same as if the Republican party had won in a landslide: a 12 to 4 majority. The average artificial partisan advantage is over two seats, and the excess artificial advantage is above $10 \%$.

The four Republican partisan gerrymanders (NC, UT, MI and $\mathrm{OH}$ ) together account for an average artificial partisan advantage of eight seats to the GOP, half the party's artificial advantage aggregated across all 42 states under consideration.

\section{Maryland}

In Maryland, the state legislature draws the districts' map. The state delegation has 8 seats. The legislature has been under Democratic control since 2011. In 2013, a group of voters challenged the Democratic-drawn maps in Court as a partisan gerrymander. A district judge 
dismissed the case in 2014 and the US Courts of Appeals affirmed this decision, ${ }^{47}$ but in 2015 SCOTUS vacated these lower court decisions and remanded the case back to the District Court, requiring that it be addressed by a panel. ${ }^{48}$ In 2018, a District Court panel ordered that new maps be drawn. ${ }^{49}$ In 2019 SCOTUS overturned the lower court ruling, holding that partisan gerrymandering claims are not justiciable, in Lamone v. Benisek. ${ }^{50}$

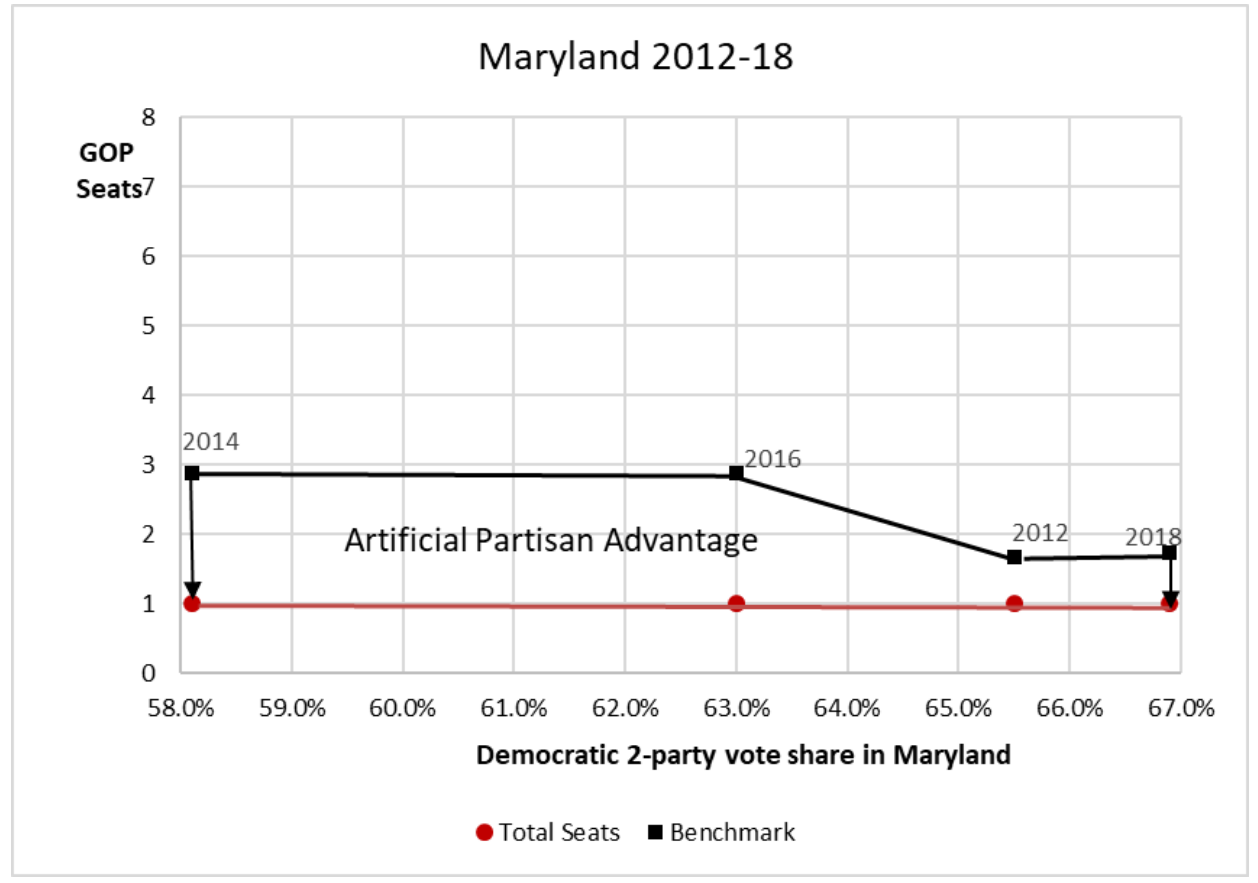

Figure OA. 6. Artificial Partisan advantage in Maryland, 2012-2018.

The evidence shows that the 2011 congressional map confers a large artificial partisan advantage to the Democratic party, with an excess artificial advantage near $10 \%$.

47 Benisek v. Mack, 11 F. Supp. 3d 516 (D. Md. 2014) and Benisek v. Mack, No. 14-1417 (4th Cir. Oct. 7, 2014).

48 Shapiro v. McManus, 136 S. Ct. 450, 577 U.S., 193 L. Ed. 2d 279 (2015).

${ }^{49}$ Benisek v. Lamone, No. 1: 13-cv-03233-JKB (D. Md. Nov. 7, 2018).

${ }^{50}$ Lamone v. Benisek, 139 S. Ct. 783 (U.S. 2019). 
In 2016, the Democratic party obtained $63.0 \%$ of the two-party vote, and won in counties with $64.0 \%$ of the population, earning 5.12 seats (out of 8 ) according to the county-based benchmark. In 2018 the Democratic party obtained $66.9 \%$ and it won in counties with $78.4 \%$ of the population, hence earning 6.27 seats according to the benchmark. With the 2011 redistricting maps, the Democratic party obtained a majority of 7-1 seats in both elections. Results for 2014 and 2012 are similar, 2014 mirroring 2016 and 2012 mirroring 2018: as in North Carolina or Ohio, the 7-1 majority for the party that drew the maps is impervious to varying electoral returns.

Averaging across all four elections, the artificial partisan advantage for the Democratic party was 1.29 seats, which corresponds to an excess artificial advantage of $9.8 \%$.

\section{Arizona}

In Arizona, an independent citizens' commission draws the districts. The state's delegation has nine seats. Its 2011 maps were perceived to favor the Democratic party. ${ }^{51}$ In November 2011, the Arizona Senate dismissed the commission's Chair, but soon after the Arizona Supreme Court reinstated her. The Arizona legislature filed suit to regain the power of redistricting, but once again lost. ${ }^{52}$

The perception that the Commission's 2011 maps favored Democrats is understandable: from 2012 to 2018 , on average the Republican party has obtained more than $54 \%$ of the two-party

\footnotetext{
${ }^{51}$ Aaron Blake. Redistricting draft map in Arizona favors Democrats. Washington Post, Oct. 4, 2011.

52 Arizona State Legislature v. Arizona Independent Redistricting Commission, 576 U.S.
} (2015). 
vote, while the Democratic party obtained less than $46 \%$, and yet both parties have alternated equally between four and five seats.

In 2012, 2014 and 2016, the Democratic party won in jurisdictional units with around to 45\% of the population, earning around 4 seats according to the seat benchmark. It obtained 5 seats in 2012 and 4 in 2014 and 2016. In 2018, the Democratic party won in a couple additional jurisdictions, earning 4.4 seats according to the benchmark. It won 5 seats in the election. Averaging across all elections, it earned just above 4 seats on average according to the benchmark, but it held 4.5 seats on average across all four terms, for an artificial partisan advantage of less than half a seat, corresponding to no excess advantage.

\section{California}

In California, redistricting maps are drawn by an independent citizens' commission. The state delegation has 53 seats.

Given the set of jurisdictional units I use, in 2012, the Democratic party won in units with 68\% of the population, earning 36 seats according to the benchmark. It won 38 seats. The 2014 result is a bit anomalous: the Democratic vote share and the population in jurisdictional units won by Democrats dropped, but the Democrats picked up another seat, to 39 , while their benchmark dropped to 32 seats. This gap closed in 2016, when the Democratic vote share increased, and the Democrats won in units with over $73 \%$ of the population earning a benchmark of over 38 seats, obtaining 39 seats once again. Finally, in 2018 they won in jurisdictional units with $82 \%$ of the population, earning 44 seats according to the benchmark, and winning 46 seats. Averaging across all four elections, the artificial partisan advantage for the Democratic party is almost 3 seats, and the excess advantage over $4 \%$. 


\section{New York}

In New York, the state's legislature is responsible for redistricting. The size of the state delegation is 27 seats. In 2011, the legislature was under divided control and was unable to agree on maps, so in 2012 a District Court adopted a map drawn by Stanford Law Professor Nathaniel Persily (then at Columbia U.).

In 2012, the Republican party won 35\% of the two-party vote and it won in jurisdictions with $15.3 \%$ of the population, corresponding to 4.1 seats according to the county-based benchmark, and it won 6 seats. In 2014, the numbers increased to close to $44 \%$ of vote share, close to $36 \%$ of population in counties won, 9.8 seats according to the benchmark, and 9 seats won. In 2016 , the Republican party obtained $36.2 \%$ of the two-party vote, and it won in counties with $26.8 \%$ of the population, earning 7.71 seats. It won 9 seats in the election. In 2018, it won $31.8 \%$ of the vote, and it won in counties with $13 \%$ of the population, earning 3.6 seats. It won 6 seats in the election.

The average artificial partisan advantage for the Republican party is 1.17 seats, and the excess artificial advantage is $2.5 \%$.

\section{Pennsylvania}

In Pennsylvania, the state legislature draws district maps. The delegation contains 18 seats. In 2011, the legislature was under Republican control.

The 2011 maps were struck down in 2018 by the Pennsylvania Supreme Court, ${ }^{53}$ which adopted instead its own remedial map, drawn under the advice of the specially appointed master

${ }^{53}$ League of Women Voters v. Commonwealth, 178 A.3d 737 (Pa. 2018). See an analysis of this case by Grofman, Bernard and Jonathan R. Cervas. Can state courts cure partisan 
Stanford Law Professor Persily. Hence the Republican legislature's 2011 maps were used up to the 2016 election, and Court maps in the 2018 election.

The legislature's 2011 maps conferred an average artificial partisan advantage of 1.85 seats to the Republican party in the 2012, 2014 and 2016 elections. As in Ohio, or in the aggregate across all states (see Figure 1 in the main text), this artificial advantage was smallest (less than one seat) in 2014 , when it was least needed because the party won by a large margin in votes and seats; and the advantage was greatest (over 3 seats) when it was most useful, in 2012, when the Democrats narrowly won the popular vote and the seat benchmark.

The 2018 Court map almost entirely eliminated this advantage: the Republican party won $44.9 \%$ of the vote, and it won counties with $46.8 \%$ of the population, earning 8.43 seats according to the benchmark. The party won nine districts, for an average artificial partisan advantage of 0.57 seats, and an excess artificial advantage of $0.4 \%$, an almost neutral map.

\section{Texas}

In Texas, the state legislature is responsible for drawing congressional districts, but in the 2011-2020 cycle, the adoption of maps in Texas has been convoluted, involving the Courts and the legislature. The delegation has 36 seats. The state legislature has been under Republican control since 2011.

The legislature drew a first set of maps in 2011, and these maps were challenged in court as a racial gerrymander. While these maps awaited pre-clearance as required by the Voting Rights

gerrymandering: Lessons from League of Women Voters v. Commonwealth of Pennsylvania. 17(4) Election L. J. 264 (2018). 
Act, a District Court issued interim maps, which were struck down by SCOTUS. The District Court issued a second set of interim maps in 2012, and in 2013, the legislature adopted permanent maps based on these second interim maps. In 2017, a District Court ruled the 2013 maps a racial gerrymander, ${ }^{54}$ but in 2018 SCOTUS overturned this ruling and dismissed the claims against the 2013 congressional maps. ${ }^{55}$

In 2012 the Republican party won in jurisdictional units (within my collection) with over 60\% of the population, corresponding to a benchmark of almost 22 seats. Since it won 24 seats, its artificial partisan advantage was a bit over 2 seats. In 2014 and 2016, the Republican party won in additional jurisdictional units, so its seat benchmark increased to between 23 and 24 seats; since it won 25 seats, its artificial partisan advantage decreased below 2 seats. In contrast, in 2018 the Republican party share of the two-party vote dropped sharply to $51.8 \%$ and the party lost many counties it had previously won. Only $52 \%$ of the population remained in jurisdictional units won by the Republican party, corresponding to 19 seats according to the benchmark. The party obtained 23 in the 2018 election.

Aggregating over all four elections, the artificial partisan advantage is above 2 seats, which corresponds to a 5\% excess artificial partisan advantage for the Republican party.

\section{Virginia}

In Virginia, the state legislature draws district maps. The state's delegation has 11 seats. Virginia's General Assembly was under divided control in 2011 and it was unable to agree on

\footnotetext{
54 Perez v. Abbott, 274 F. Supp. 3d 624 (W.D. Tex. 2017).

${ }^{55}$ Abbott v. Perez, 138 S. Ct. 2305 (2018).
} 
redistricting maps on that year. Once the GOP gained unified control of the state's legislature, it approved redistricting maps in 2012. In 2015, these maps were struck down as a racial gerrymander by a District Court. ${ }^{56}$ Since the legislature was unable to draw new maps, the Court adopted instead a map drawn by a panel of federal judges. This Court-drawn map was in use in the 2016 and 2018 election.

The legislature's 2012 congressional map conferred an average artificial partisan advantage of 1.57 seats to the Republican party in the 2012 and 2014 elections. As in Pennsylvania, Ohio, Michigan or in the aggregate of the nation, the partisan advantage was greatest (two seats) when it was most useful in 2012, helping to turn a Democratic narrow victory in votes and benchmark seats into a Republican majority in the House. The advantage was smallest (only one seat) in 2014, when it was less relevant. The excess artificial advantage of these racially gerrymandered maps was near $10 \%$.

The Court-drawn map reduced this Republican advantage. In 2016, the Republican party obtained $49.8 \%$ of the two-party vote, and won in counties with $50 \%$ of the population, earning 5.5 seats according to the county-based seat benchmark. It won 7 districts. In 2018, it obtained $43 \%$ of the two-party vote, and it won in counties with $34.9 \%$ of the population, earning 3.84 seats according to the benchmark. It won 4 districts. Averaging over the two elections, the artificial partisan advantage is 0.83 , with an excess artificial advantage of only $3 \%$.

\footnotetext{
${ }^{56}$ Page v. Virginia State Board of Elections, Civil Action No. 3: 13cv678 (E.D. Va. June 5, 2015).
} 


\section{SECTION OA.2. LIMITATIONS AND SUGGESTED REMEDIES}

In this section I discuss all the caveats and limitations of the measure of artificial partisan advantage that I am aware of, and I suggest some remedies.

\section{States with missing data: Florida.}

To compute the artificial partisan advantage, we need voting tallies in every race, including uncontested races. Two states do not run elections for uncontested seats: Oklahoma, and Florida.

In Oklahoma, the absence of data on uncontested races is inconsequential: because the Republican party obtains most votes in every county despite collecting no votes in seats it wins uncontested, the seat benchmark is unaffected by missing data from uncontested seats.

In contrast, in several counties in Florida, not counting votes in uncontested districts determines which party gets the most votes: in these counties, if the election for an uncontested seat had been held and the votes for the winner tallied, the party of the winner of the uncontested race would have won the county, but if we do not hold an election for this seat (and hence we do not tally any votes for the winner of this seat), the opposite party wins.

A possible solution to compute the artificial partisan advantage in Florida despite this missing data is to impute the votes that the party that won an uncontested seat would have obtained in each precinct had an election been held. I pursue this approach as part of the robustness check that uses voting results from the 2012 and 2016 US Presidential election. With this data, the 2012-2014 map exhibits an artificial partisan advantage for the GOP of more than 3 seats, with an excess advantage over $9 \%$ of the delegation. This map was later struck by the Florida Supreme Court as a partisan gerrymander; the replacement map, in use in the 2016 election, exhibits a very slight (less than $1 \%$ ) excess partisan advantage for the Democratic party. 
In addition, I drop Maine from the 2018 results. Maine adopted the Alternative Vote rule for the 2018 election. Under the Alternative Vote, voters rank as many candidates as they wish. Counting proceeds in rounds, eliminating in each round the candidate with fewest top finishes; votes for her are transferred to the next ranked candidate in the subsequent round of voting, until a candidate obtains a simple majority of votes, at which point the counting stops.

Since Maine did not continue counting additional rounds in precincts that belong to a district in which a candidate has already won a simple majority, it does not provide the data necessary to compute who would have won in all counties. Unlike in Florida, the data exists, in the original ballots, but this data has not been tallied nor made public.

\section{Sensitivity.}

Any measure that relies exclusively on actual election results evaluates a map based on very few data points: only one per election. We may wonder about the sensitivity of the measure to small changes in election outcomes. We can evaluate whether the measure of the artificial partisan advantage is robust to small changes in voting outcomes by computing the measure for a counterfactual election with similar results.

Recall that SCOTUS is "wary of adopting a constitutional standard that invalidates a map based on unfair results that would occur in a hypothetical state of affairs. "57 I follow SCOTUS' guidance on this point: the measure of artificial partisan advantage relies exclusively on actual election results. I suggest using counterfactuals only as a sensitivity analysis, following a principle of caution: if actual election results induce a presumption that a plan is a partisan gerrymander, we can give the plan a second chance by using counterfactuals to check whether the plan

57 Justice Kennedy's Opinion of the Court in LULAC v. Perry, 548 U.S. 399, 420 (2006). 
performs sufficiently better under alternative hypothetical scenarios to undermine the initial finding against the map... but I do not suggest using counterfactuals to criticize a map that performs well with actual data.

I conduct a sensitivity analysis of the artificial partisan advantage for the maps in the states of North Carolina, Utah, Michigan, Ohio and Maryland maps for each of the four elections. I recompute the seat benchmark and the artificial partisan advantage for any counterfactual in which a fixed fraction up to $1 \%$ of Republican votes in each county and district switched to the Democratic party; and for any counterfactual in which up to $1 \%$ of Democratic votes switched to the Republican party. ${ }^{58}$

Figure OA.7 shows the results of this sensitivity analysis in North Carolina. The graph of the benchmark number of seats jumps at each vote share at which the popular vote in a county flips from one party to the other; the size of the jump varies in proportion to the county's population. The total number of seats jumps by one seat at the counterfactual vote share at which a district flips. Lines connect counterfactuals associated to the actual election result used to generate them. ${ }^{59}$

\footnotetext{
${ }^{58} \mathrm{~A}$ different counterfactual in which a common share of votes switched in all counties generates absurdities such as votes over $100 \%$ or below $0 \%$ for a party in counties in which only one party runs. The counterfactuals I run avoid this problem, and always generate meaningful results, by switching a fixed fraction of the votes cast for a party, not of the total number of votes

${ }^{59}$ Counterfactual arguments lose meaning if they are too distant from real data. Without bounds on this distance, any map performs well for some counterfactual. I only consider counterfactuals in which up to $1 \%$ of voters for a given party switch their vote.
} 
North Carolina 2012-18

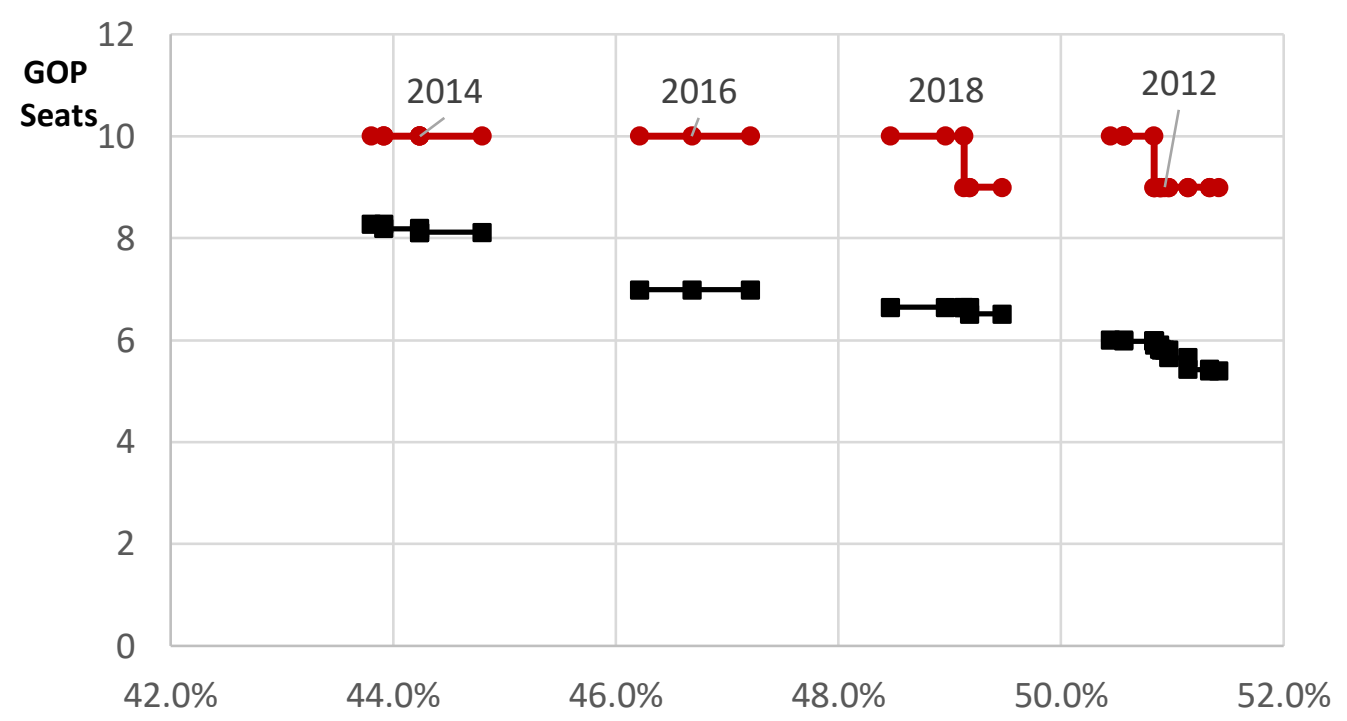

Democratic 2-party vote share in NC

$\longrightarrow$ Total seats $\rightarrow$ Benchmark

Figure OA.7. Sensitivity analysis for North Carolina, number of seats.

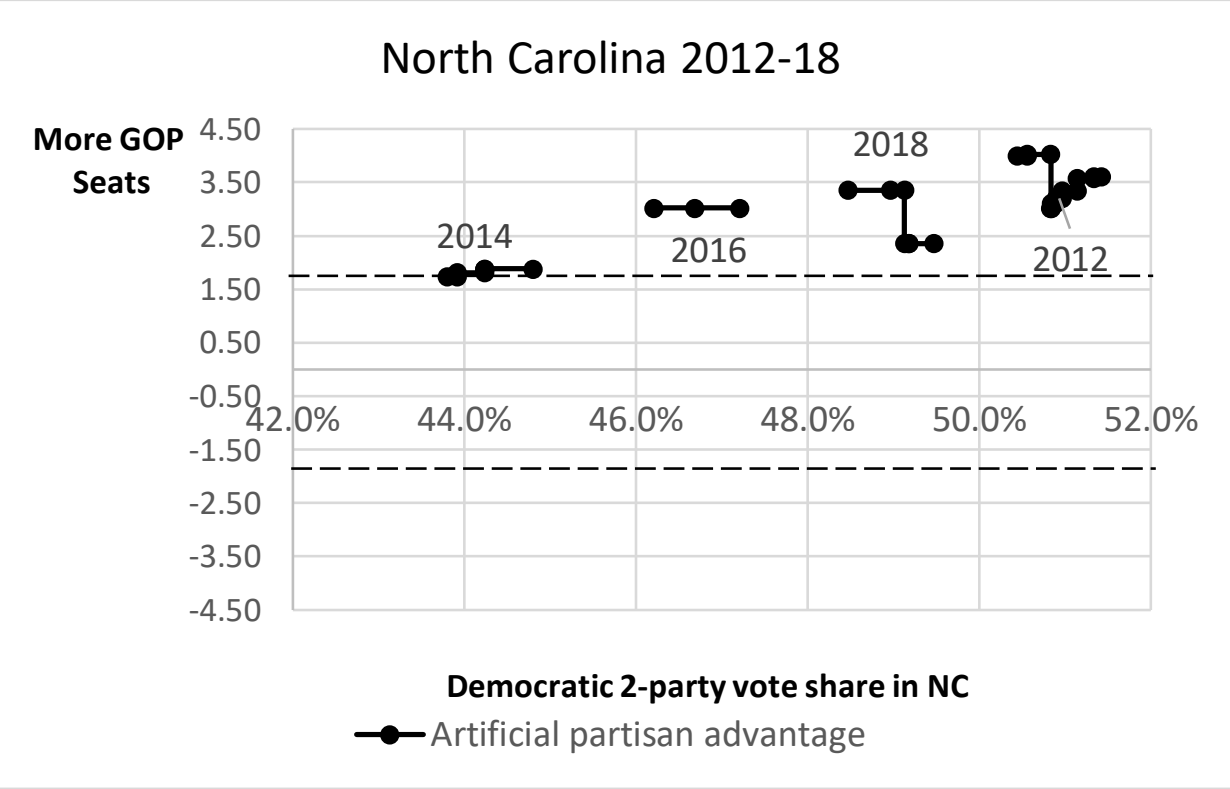

Figure OA.8. Sensitivity analysis in North Carolina; artificial partisan advantage 
In Figure OA.8, the band limited by the dashed lines is the range of values with excess artificial advantage no greater than $10 \%$. North Carolina's map is outside this range for any counterfactual vote share in the range from the smallest to the largest vote share in an actual election.

The maps in North Carolina, Utah, Michigan and Ohio perform similarly -or slightly worseunder the counterfactual voting results (see figures OA.9 - OA-16). The sensitivity analysis provides no evidence to overcome the presumption derived from actual election results that these maps are partisan gerrymanders with an excessive artificial advantage.

On the other hand, the map in Maryland, which conferred an average excess artificial advantage close to $10 \%$, performs better in some of the counterfactuals. The map confers an artificial advantage to the Democratic party in every counterfactual, but the magnitude is smaller in some of these counterfactuals. This sensitivity analysis weakens the evidence against the Maryland map, evidence that was the weakest among these five states to begin with.

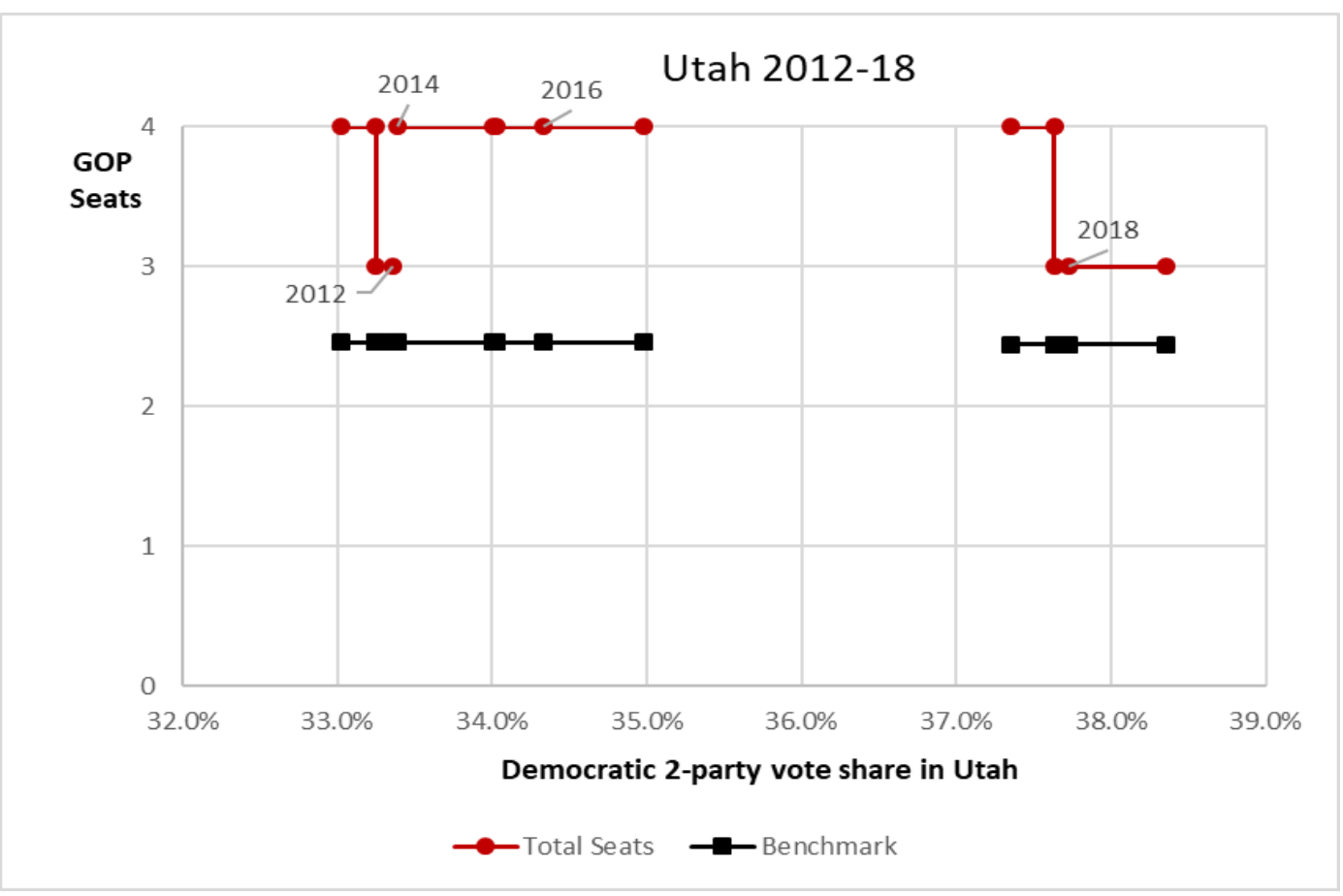

Figure OA.9. Sensitivity analysis for Utah, number of seats. 


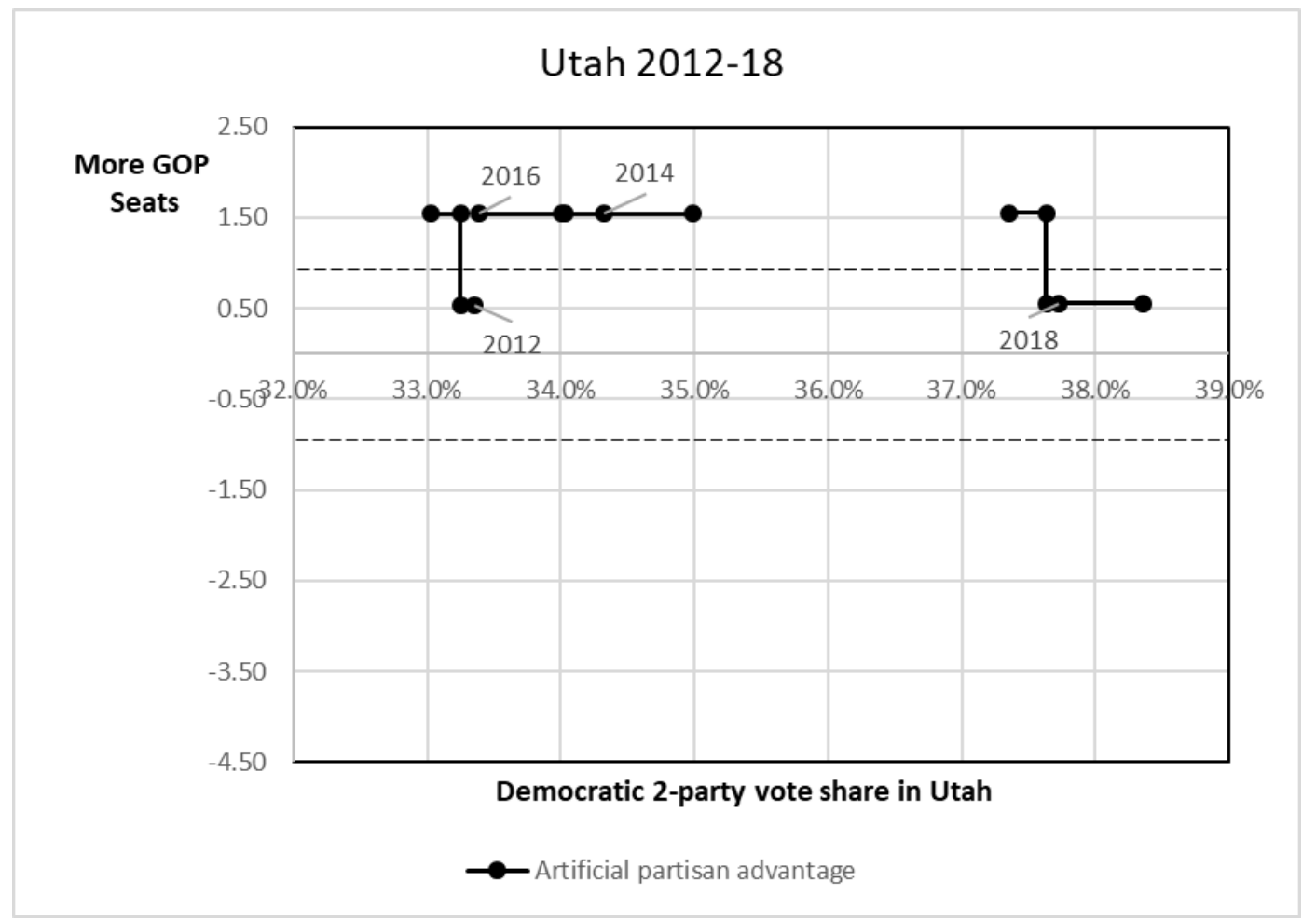

Figure OA.10. Sensitivity analysis for Utah, artificial partisan advantage. ${ }^{60}$

60 The counterfactuals with up to $1 \%$ of one party's vote switching computed with respect to each election overlap in Utah. When they do, I only plot the counterfactual closest to an actual election result, and not the one derived from a greater deviation from an actual election result. For instance, for the counterfactual in which at least $0.4 \%$ of all Democratic voters in 2016 had switched to the Republican party, the Republicans would win Salt Lake county, and their benchmark number of seats would increase to close to 4 , but for such a counterfactual vote share, the 2012 actual election result is a closer base point. 


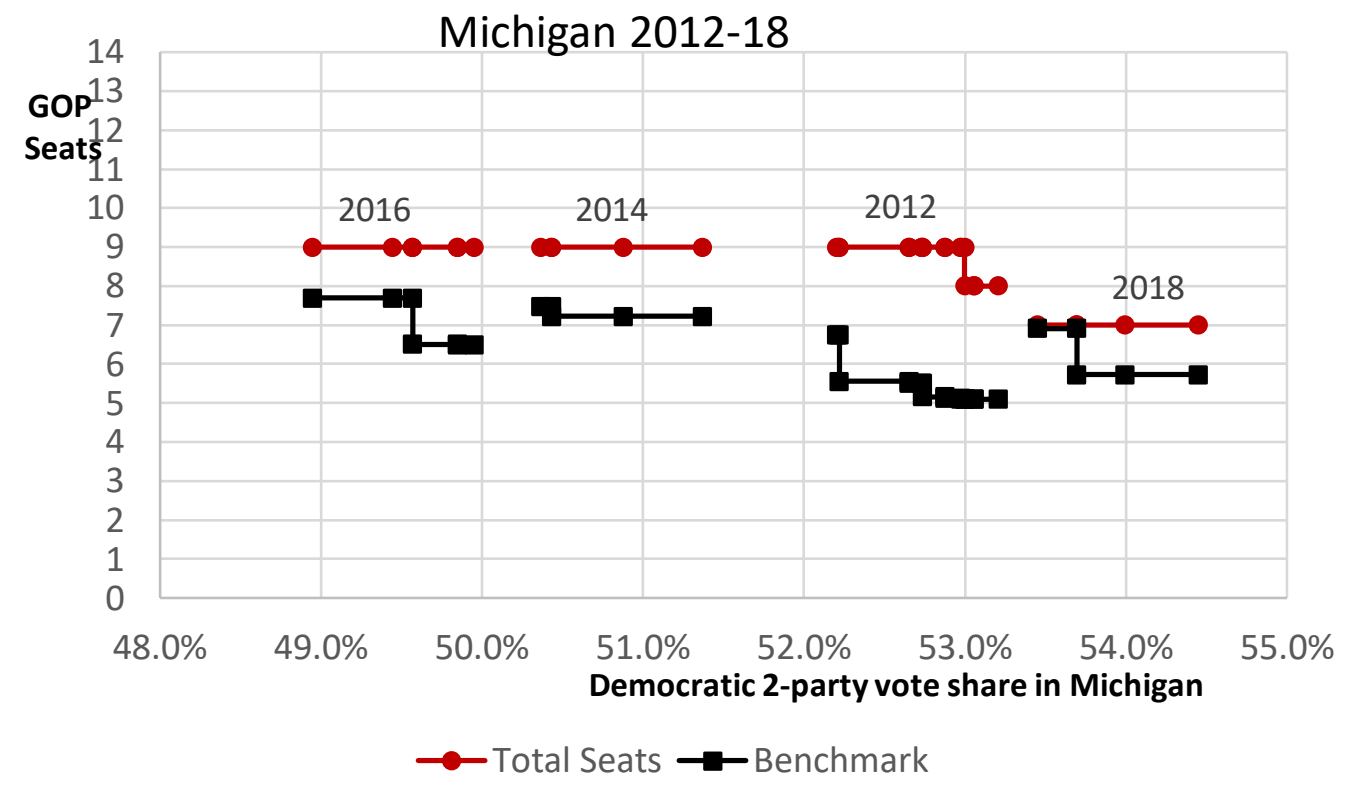

Figure OA.11. Sensitivity analysis for Michigan, number of seats.

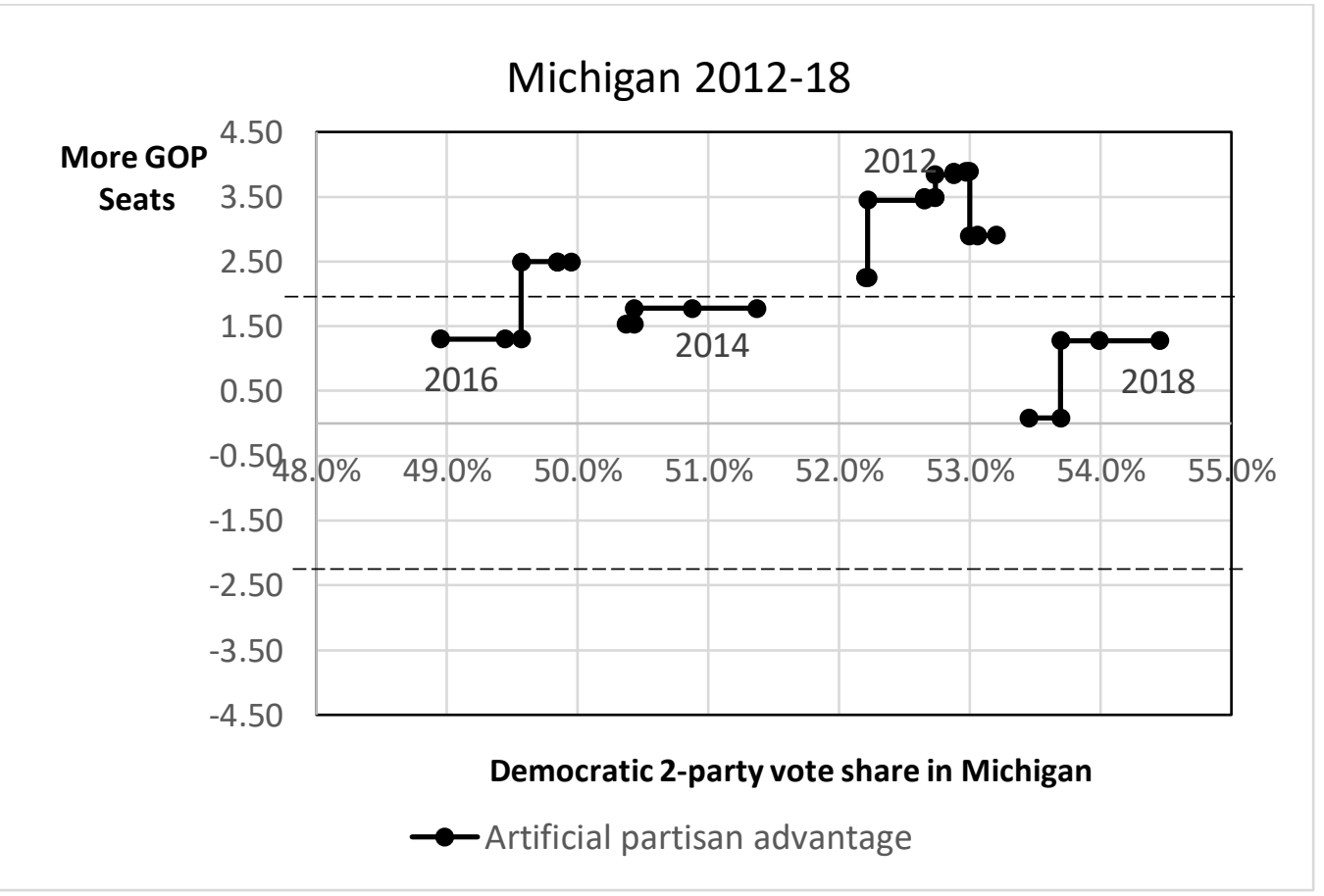

Figure OA.12. Sensitivity analysis for Michigan, artificial partisan advantage 
Ohio 2012-18

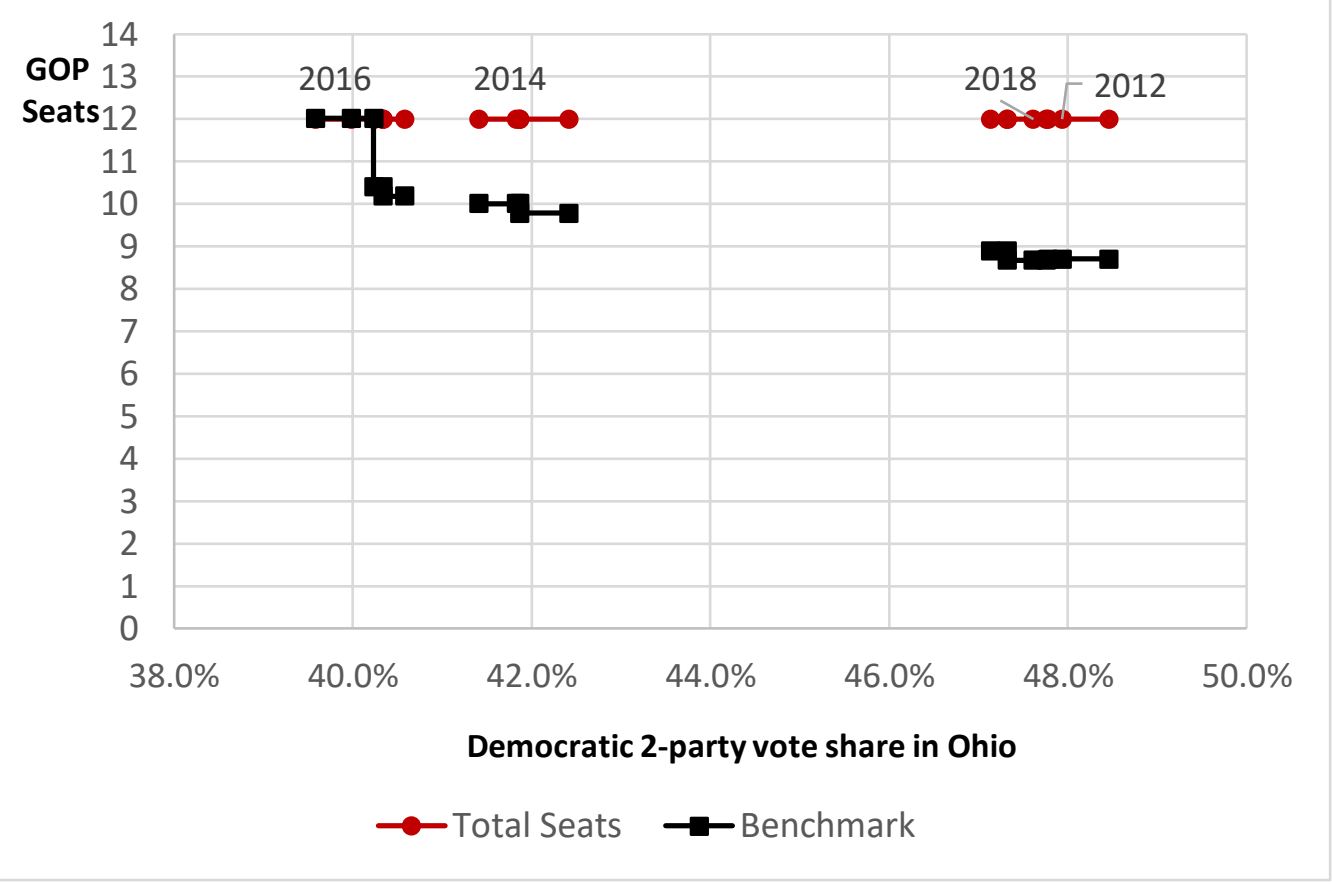

Figure OA.13. Sensitivity analysis for Ohio, number of seats.

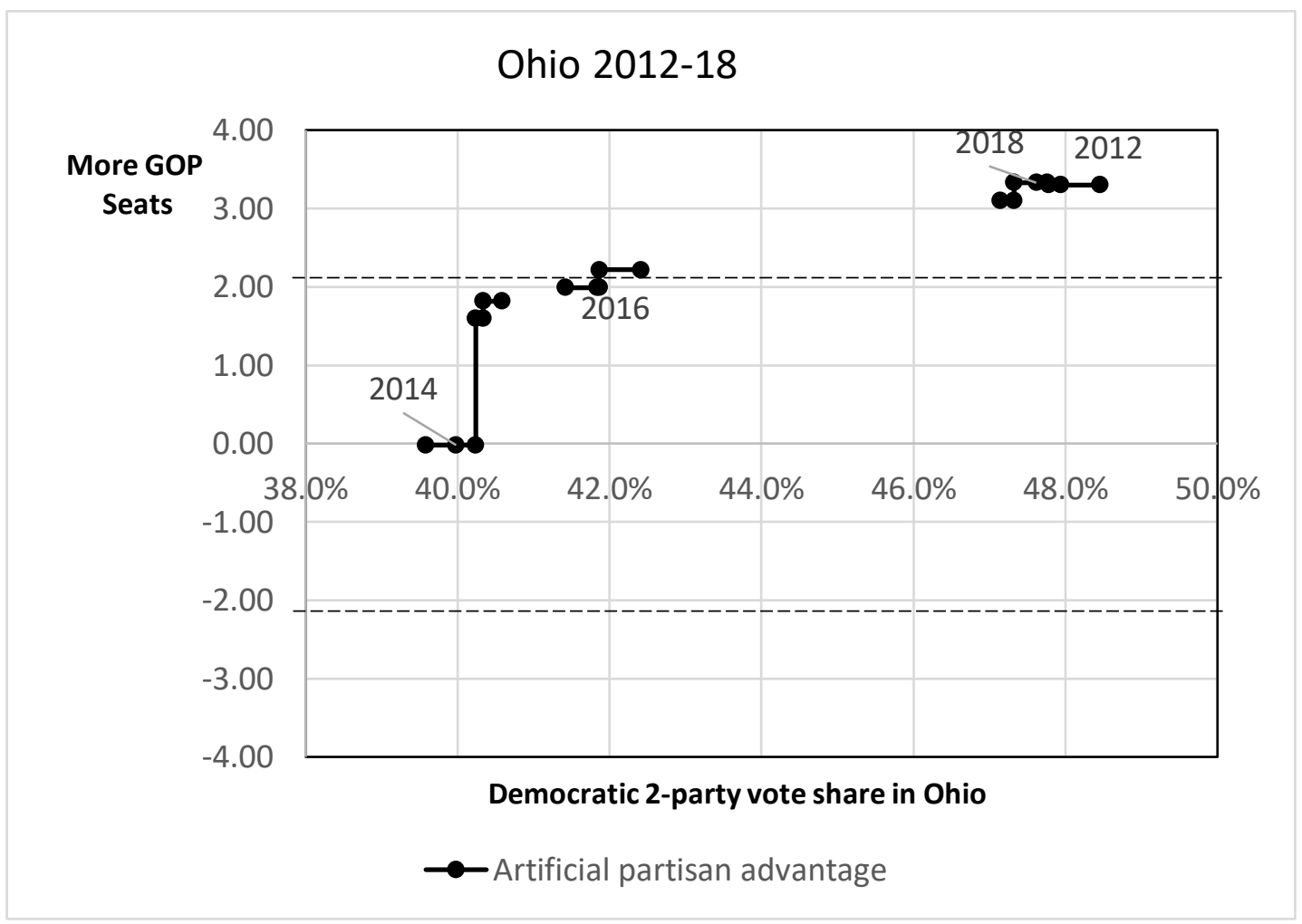

Figure OA.14. Sensitivity analysis for Ohio, artificial partisan advantage. 
Maryland 2012-18

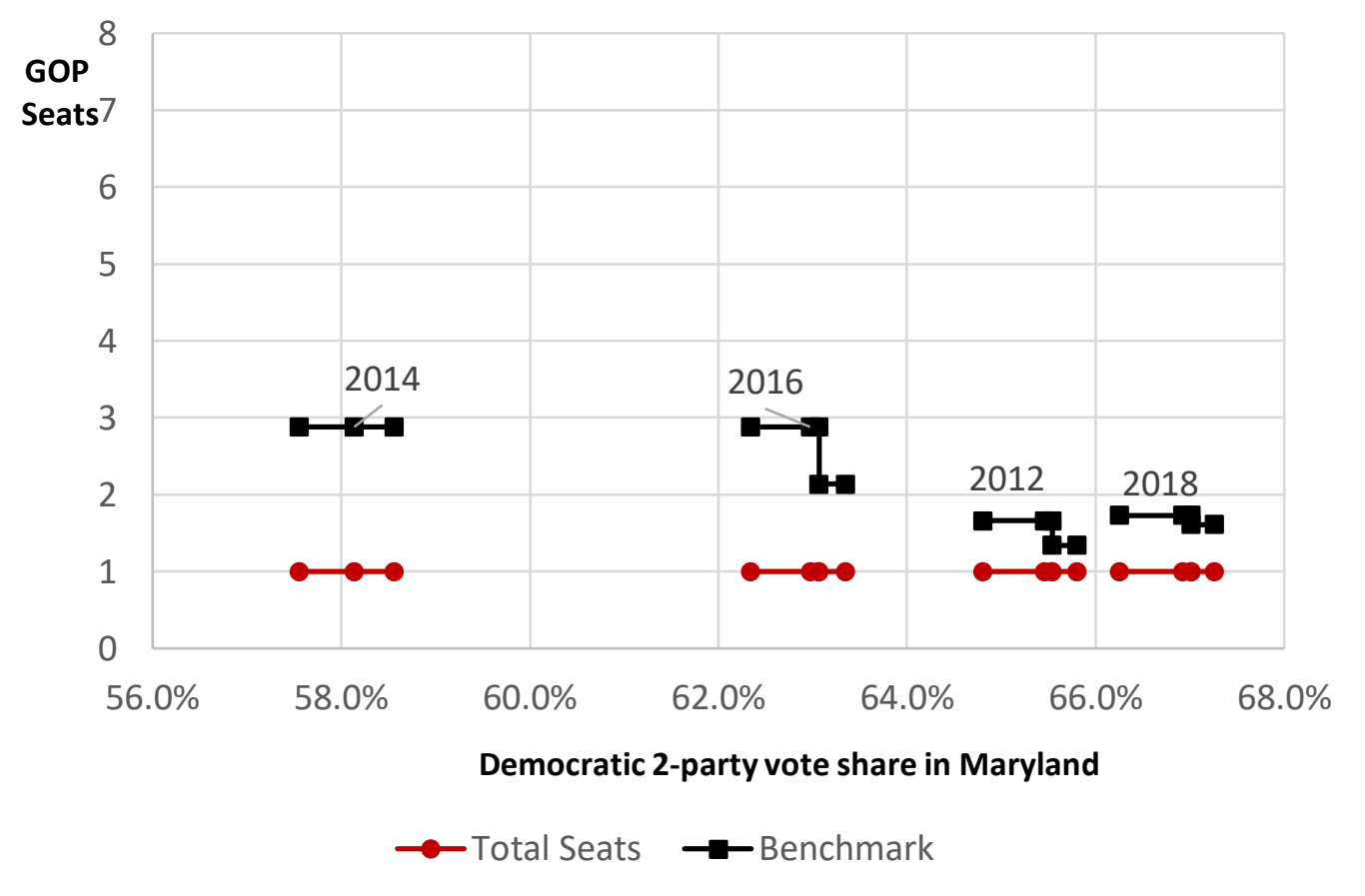

Figure OA.15. Sensitivity analysis for Maryland, number of seats.

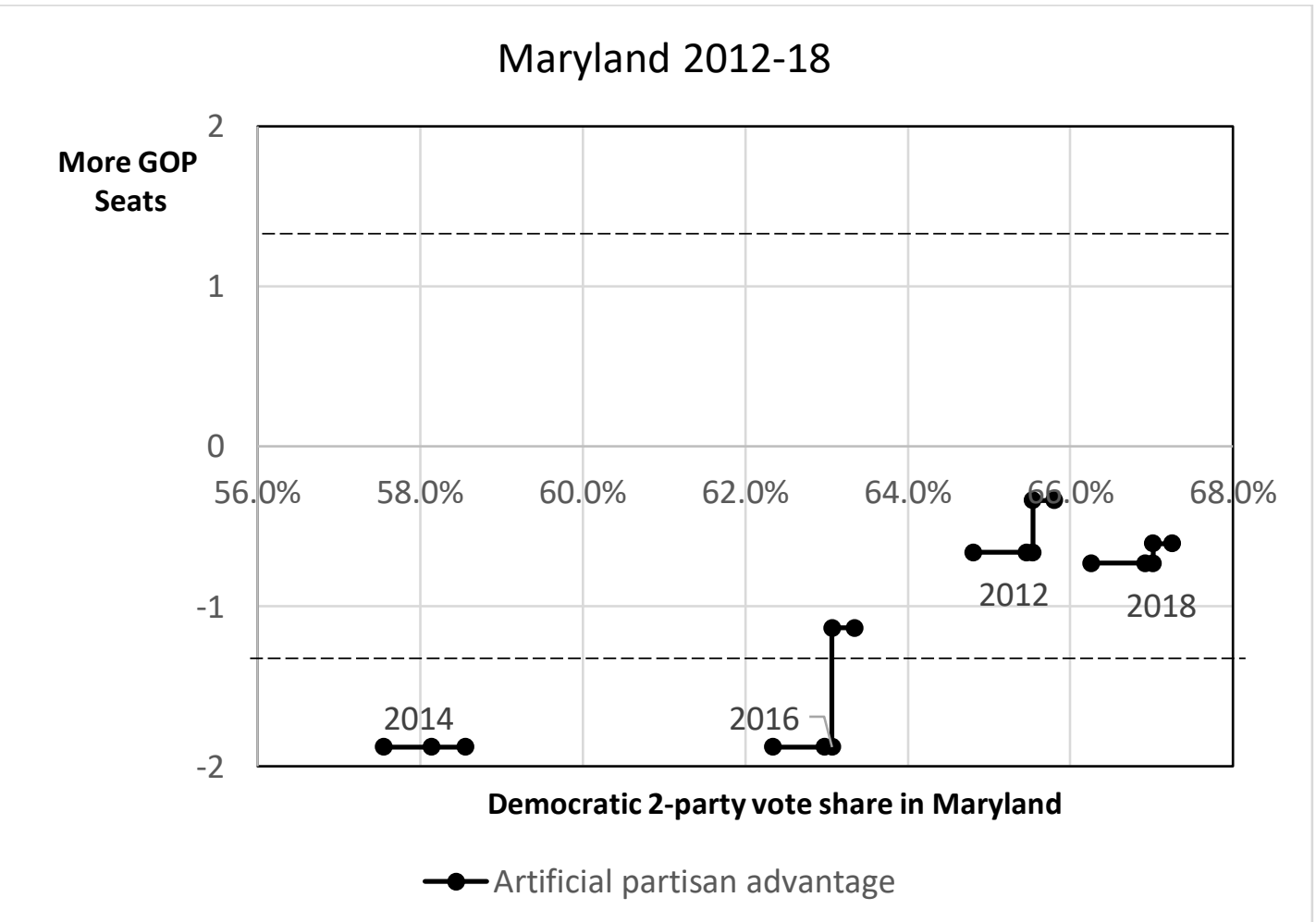

Figure OA.16. Sensitivity analysis for Maryland, artificial partisan advantage. 


\section{Incomplete judicial test.}

The artificial partisan advantage provides a notion of partisan fairness in redistricting that corresponds to a clear normative benchmark: a redistricting map is "fair" if it approximates the seat share that we would obtain without drawing electoral districts, apportioning seats instead by jurisdictional units. ${ }^{61}$

The artificial partisan advantage is then the seat difference between the actual outcome and this benchmark. Since this absolute measure of seats will tend to be larger in states with more seats, to compare the measure across states of different sizes I also propose the excess artificial advantage, which is the measure of artificial partisan advantage in excess of a rounding margin of 0.5 seats, divided by the total number of seats in the delegation.

Given the normative standard given by the county-based benchmark, a map with zero excess partisan advantage is neutral and "fair." An open question remains: how great a deviation from fairness is tolerable, and what's the cutoff beyond which a map is illegal?

In previous drafts of this work, I suggested using a threshold of $10 \%$ of excess artificial advantage to regard a redistricting map as a partisan gerrymander if its excess artificial advantage is above this threshold. This $10 \%$ cutoff finds precedent in previous SCOTUS decisions: In 1983, and most recently in 2016, SCOTUS used $10 \%$ as the threshold of population differences across

61 To be more precise, by assigning seats to each jurisdictional unit (counties, cities or townships) closest in size to the current congressional districts. In most states, these units are the counties. 
districts beyond which the difference is a prima facie evidence of discrimination. ${ }^{62}$ I suggested using the same $10 \%$ threshold to evaluate redistricting plans under federal law.

As long as partisan gerrymandering claims remain non-justiciable in federal courts, the question of identifying a homogeneous federal standard to evaluate all plans under federal law is moot. The question of degree about how much partisan unfairness is tolerable and legal shifts to the states.

The answer will depend on the language requiring partisan fairness in each state's Law. The answer may take into account the excess partisan advantage; it could check the robustness of this measure against the sensitivity analysis in the previous subsection, or it could use a collection of measures to identify a robust finding of unfairness; it can take into consideration idiosyncratic explanations for a larger than normal artificial partisan advantage in a given particular case; ${ }^{63}$ and it can weigh violations of partisan fairness compared to the map's performance in other

62 See Brown v. Thomson, 462 U.S. 835 (1983) and Harris vs Arizona Independent Redistricting Commission 578 US _ (2016).

${ }^{63}$ For some configurations of the geographic distribution of voters, any redistricting map with contiguous, compact districts will feature an excess advantage greater than $10 \%$. These configurations are implausible, but here is an example. Consider a linear state (say along a road) from East to West that must be divided into three districts with equal population. Assume the easternmost and westernmost counties each have $1 / 6$ of the population, and that Party $p$ wins two thirds of the votes in the easternmost and westernmost counties, and no votes elsewhere. Party $p$ wins in counties with $1 / 3$ of the population, so it earns one seat according to the countybased benchmark. A map that yields zero seats for Party $p$ confers an excessive partisan advantage for the other party. However, any map with contiguous districts would result in Party $p$ winning no seats. 
criteria such as compactness or respect for jurisdictional boundaries... In any case, confronted with evidence of partisan unfairness in gerrymandered maps, state courts will face the same question posed by the Opinion of the Court in Rucho v. Common Cause (2019): "How much is too much?" Staring at the evidence from North Carolina and Maryland 2011 congressional maps, Justice Kagan offered an emphatic answer in her Dissent (joined by three other justices) in Rucho: "This much is too much."

It will next be up to the states' courts to decide whether the partisan advantage in each challenged map is acceptable, or whether it is too much under state law.

\section{Arbitrary unit selection: Modifiable Area Unit Problem (MAUP).}

The definition of the artificial partisan advantage is based on a comparison to a benchmark based on a partition of the state into jurisdictional units. Change the collection of jurisdictional units used to define the benchmark (say from counties to townships), and the definition of the measure changes. It follows that the artificial partisan advantage could be subject to a standard inference problem: The Modifiable Area Unit Problem (MAUP). ${ }^{64}$ This problem arises in application in which primary data is aggregated into geographical units, and data at the aggregated unit level is used to estimate a variable of interest; the problem is that choosing different geographical units of aggregation can lead to different results.

I argue that the definition of the artificial partisan advantage measure is not subject to MAUP because the area unit is not arbitrarily modifiable, in the sense that any modification incurs in a normative loss. A unique collection of jurisdictional units enjoys the normative appeal of most

\footnotetext{
${ }^{64}$ For a standard treatment of this problem see for instance King (1997), Ch. 14.
} 
closely preserving the granularity of the units of vote aggregation (or, put differently, the size of the unit of representation): this collection is the collection of jurisdictional units closest in size to the districts that need to be drawn. In 32 out of 42 states, these units are the counties, and the benchmark to use is the one constructed based on the county map.

An alternative normative criterion for identifying the most appropriate level of jurisdiction to use for the benchmark is substantive and historical: we would like to use jurisdictions that define communities and have been historically used as units of representations. In many states, these are the counties. In New England states, these are the towns or townships, and in Louisiana these are the parishes; so in these states, a robustness checks using towns and townships to construct the jurisdictional benchmark is warranted according to this second normative criterion. I conduct this robustness analysis, constructing the benchmark based on a partition of the state into towns, townships and parishes for the New England states (Maine, New Hampshire, Massachusetts and Connecticut) and Louisiana. ${ }^{65}$ I find that results in each of these states are qualitatively similar under either the choice of jurisdictions (counties; or townships and parishes) across elections. I report the comparison of average artificial partisan advantage and, in parenthesis, excess artificial partisan advantage computed according to towns, townships and parishes in the following table, with the benchmark (based on jurisdictions closest in size to congressional districts) alongside for comparison.

\footnotetext{
${ }^{65}$ For CT, the data by townships is only readily available for the 2012, 2014 and 2016 elections;
} for the other view states, I use all four elections from 2012 to 2018. 


\begin{tabular}{|c|c|c|}
\hline TABLE OA.1. & $\begin{array}{c}\text { Excess advantage based on } \\
\text { townships and parishes }\end{array}$ & Benchmark excess advantage \\
\hline Connecticut & $-0.63(-2.7 \%)$ & $-0.20(0 \%)$ \\
\hline Louisiana & $-0.16(0 \%)$ & $0.14(0 \%)$ \\
\hline Maine & $0.10(0 \%)$ & $-0.11(0 \%)$ \\
\hline Massachusetts & $-0.32(0 \%)$ & $0(0 \%)$ \\
\hline New Hampshire & $-0.60(-5.1 \%)$ & $-0.67(-8.5 \%)$ \\
\hline Rhode Island & $-0.14(0 \%)$ & $-0.02(0 \%)$ \\
\hline
\end{tabular}

In the benchmark analysis, I follow the population size criterion (proximity in population size to the districts) rather than the historical unit of representation criterion. According to the population size criterion, in ten states (AZ, CA, IL, MA, MI, NV, NY, PA, TX and WA), some counties are too big; smaller jurisdictional units such as townships are closest in size to congressional districts. The axiom of seeking the units closest in size to the district requires breaking up every county of population size greater than two congressional districts $(1,415,000$ inhabitants $)$ into townships. There are 21 such counties in the 42 states under consideration (out of a total of 2,844 counties).

As a robustness check, in the states with large counties we can modify the areas of aggregation, using higher population size cut-offs to break up counties into smaller jurisdictional units of aggregation. Results (available from the author, or easily inferable directly from the datafiles) are very similar using a population cutoff equal to the population of three, four or five districts. Changing the size cutoff from two to three, four of five districts, only affects results in 
California (where it halves the average Democratic artificial partisan advantage from 3 to 1.46 seats if the cutoff is three, and reduces it to 2 or 2.5 seats if the cutoff is respectively four or five districts); and in Arizona, Illinois, Nevada, New York and Texas, where the effect is small (no more than 0.2 seats). The average Republican artificial partisan advantage in the aggregate across all 42 states computed with a population size cut-off to break counties into townships equal to three districts is 18.5 seats, 18 seats computed with a cutoff of four, and 17.5 seats with a cutoff of five districts, compared to 17 seats with the more compelling cutoff of size equal to two congressional districts. As a thought-experiment, the GOP also enjoys an average artificial partisan advantage of 17 seats relative to the benchmark that aggregates votes at the state level (so each state becomes a winner-take-all).

As an alternative robustness check, we can consider aggregating votes at smaller units of aggregation. The smallest units that report aggregate results are the voting precincts. Aggregating at the precinct level has two caveats, one normative, the other one practical. The normative one is that these voting precincts are not jurisdictional divisions, they are not communities with historical grounds to consider them units of representation. The practical caveat is the limited availability of data on population by precinct. With these caveats in mind, I compute the artificial partisan advantage aggregating votes at the precinct level for the state of Ohio in the 2012, 2014, 2016 and 2018 US House election; for North Carolina in the 2012 and 2016 US Presidential election, and for Michigan in the 2016 US House election. The choices, selected from the five states with greatest excess artificial partisan advantage as computed in the main analysis (NC, UT, OH, MI and MD) are limited by data availability. 
The Ohio data is available from the Ohio Secretary of State, using their reported registered voters per precinct as an imperfect proxy for population by precinct. The data for North Carolina and Michigan is from the Metric Geometry and Gerrymandering Group (MGGG), and the year and election selection is constrained by the data made public by MGGG.

The artificial partisan advantage aggregating by precinct in these cases is as follows: In North Carolina it was 2.39 seats in 2012 and 2.45 seats in 2016, for an excess average artificial advantage of 14.7\%; in Ohio it was 2.99 seats in 2012, 1.07 seats in 2014, 1.26 seats in 2016 and 2.68 seats in 2018, for an excess artificial advantage of 9.4\%; and in Michigan in 2016 it was 1.30 seats, the same as estimated using counties as units of aggregation.

At the extreme of disaggregation into the smallest units lies proportional rule, where each vote corresponds to its proportional share of a seat. In the aggregate across all states, and on average over all four elections to the US House from 2012 to 2018, the GOP enjoyed an advantage of 12 seats over the proportional benchmark.

Overall, we see then that aggregate results -and state results in most states- are therefore qualitatively robust across different size cutoffs for the jurisdictional units of aggregation.

\section{Small States.}

States with four or fewer seats present additional challenges to measure partisan advantage. The standard approach is to simply drop them from the analysis. ${ }^{66} \mathrm{~A}$ strength of the artificial partisan advantage measure is that it can be applied to states of any size. However, we must be aware of a subtlety in interpreting the results, as follows.

\footnotetext{
${ }^{66}$ See for instance Royden and Li (2017).
} 
Small states, by the very nature of their size, are more likely to generate extreme results: their maps are more likely to be measured as neutral, with zero excess artificial advantage, or as an extreme partisan gerrymander, and they are less likely to show the small or moderate excess artificial advantage typical of large states. This phenomenon is best illustrated by example: in 2016, the Republican party won the popular vote in counties with $51.6 \%$ of the population of Maine, so its county-based seat benchmark was 1.03 (out of 2 seats in the state). If the map is such that the Republican party gets exactly 1 seat, the excess artificial advantage is zero, while if the party gets 0 or 2 seats, the map is presumed to be an extreme partisan gerrymander: with an excess artificial advantage of around $25 \%$. That is, based on the 2016 voting records, any map for Maine could only be measured as either neutral, or as the worst gerrymander in the nation. ${ }^{67}$

In contrast, if a party were to gain the popular vote in counties with $51 \%$ of the population of California, the excess artificial advantage is zero only if the party wins exactly 27 seats. Given that election outcomes are uncertain, the party is unlikely to obtain exactly 27 seats for any map with some competitive districts. On the other hand, if the party wins anything between 22 to 26 or 28 to 32 seats (a most likely outcome), the excess artificial advantage is positive but below $10 \%$.

So, while the average excess artificial advantage is approximately constant in state size, by nature of the limited set of possible outcomes, maps in small states are more likely to yield an extreme measure of excess artificial advantage (either zero, or very high). Therefore, when we observe these extreme measures in a small state, we must interpret them as less exceptional than they would be for larger states.

${ }^{67}$ In the event, the Republican party obtained one seat, so the Maine map is measured as neutral. 
This nuance implies that the sensitivity analysis, accumulating results from various elections, or using additional measures, may be advisable before we invalidate a map from a small state, even if its measure of excess artificial advantage appears extreme.

This is an exhaustive list of the limitations and challenges in the use of the measure of artificial partisan advantage that I am aware of. I invite and welcome further criticism, in the conviction that "ideas should be carefully tested and subjected over time to serious critical examination before they are used to affect policy." (Chambers, Miller and Sobel, 2017). 
ADDITIONAL REFERENCES

-King, Gary. A Solution to the Ecological Inference Problem: Reconstructing Individual Behavior from Aggregate Data. Princeton: Princeton University Press. 